\title{
Why do people play games? A meta-analysis
}

\section{Authors: Hamari Juho \& Keronen Lauri}

\begin{abstract}
During the last decade games have arguably become the largest form of leisure information systems (IS). However, today games are also increasingly being employed for a variety of instrumental purposes. Although games have garnered a substantial amount of research attention during the last decade, research literature is scattered and there is still a lack of a clear and reliable understanding of why games are being used, and how they are placed in the established utilitarian-hedonic continuum of information systems. To address this gap, we conducted a meta-analysis of the quantitative body of literature that has examined the reasons for using games (48 studies). Additionally, we compared the findings across games that are intended for either leisure or instrumental use. Even though games are generally regarded as a pinnacle form of hedonically-oriented ISs, our results show that enjoyment and usefulness are equally important determinants for using them (though their definitive role varies between game types). Therefore, it can be posited that games are multi-purpose ISs which nevertheless rely on hedonic factors, even in the pursuit of instrumental outcomes. The present study contributes to and advances our theoretical and empirical understanding of multi-purpose ISs and the ways in which they are used.
\end{abstract}

Keywords: Meta-analysis; meta-sem; technology acceptance; games; gamification; multipurposed information systems 
RUNNING TITLE: Why do people play games? A meta-analysis

\section{Why do people play games? A meta-analysis}

\section{INTRODUCTION}

During the last decade games have become an established vein of entertainment, consumer culture, and essentially a common part of people’s daily lives (Mäyrä \& Ermi 2014; Yi 2004). In the United States alone, 59\% of the population plays computer games while revenues of the computer games industry exceed US \$15 billion (ESA 2014). However, in addition to the increased penetration of games, the ways in which people play and employ games have also become more varied. The long-tail is getting longer: there are more different kinds of games available for a multitude of different platforms that cater for differing gaming needs (Hamari \& Tuunanen 2014; Kallio et al. 2011; Yee 2006a; Yee 2006b), for widening audiences (Greenberg et al. 2010; Griffiths et al. 2003; Griffiths et al. 2004; Hartmann et al. 2012; Ijsselsteijn et al. 2007; Jansz et al. 2010; Koivisto \& Hamari 2014; Mäntymäki \& Riemer 2014; Mäntymäki \& Salo 2015; Mäyrä \& Ermi 2014; Williams et al. 2008; Williams et al. 2009; Zhou et al. 2011), and which use a wide variety of business models (Alha et al. 2014; Alha et al. 2016; Hamari et al. 2017a; Hamari et al. 2017b Hamari \& Järvinen 2011; Hamari \& Lehdonvirta 2010; Lehdonvirta 2009; Mäntymäki \& Salo 2011; Mäntymäki \& Salo 2013). Moreover, games are increasingly used for instrumental purposes (e.g. gamification, serious games, simulation games, and games-for-purpose) (Hamari et al. 2014; Hamari et al. 2016; Huotari \& Hamari 2016; McGonigal 2011) as well as increasingly as a eSport (Hamari \& Sjöblom 2017; Sjöblom \& Hamari 2016; Taylor 2012), although commonly held legacy causes most to still consider games as mere hedonic systems that are solely played by pre-adolescent males. 
RUNNING TITLE: Why do people play games? A meta-analysis

It is evident that significant amounts of complexity, opaqueness and disconnect exist as to how games are generally perceived, as well as a theoretical turbulence in academia pertaining to their definition and position. Games are indeed a rather peculiar type of information system.

Developments in information technology have pushed games into a variety of areas of human life, and have diversified in terms of their different uses, motivations, and users. Today, games and gameful information systems are employed in a variety of contexts, organizations, and for a multitude of differing purposes. Therefore, the reasons and motivations as to why people use them can also be expected to vary. Thus far however, games have commonly been seen as a singular type of technology: “Gamers just want to have fun” (Wu \& Li 2007; Yoon et al. 2013). However, it is evident that games present themselves as more manifold and multifaceted types of information systems that continue to prove an isle of theoretical ambiguity in the information systems field.

Due to this increasing divergence, the impact and significance of games as information systems, and understanding the nature of games and why people use them have therefore become especially timely and fascinating. Even though the topic has attracted substantial scholarly interest during the last decade (see e.g. Table 1), the current body of literature seems to be scattered and amorphous. Especially noted is that the body of literature on games is dispersed into a wide variety of different types of games such as experimental educational games (Bourgonjon et al. 2010; Kuo et al. 2011), mobile social networking games (Wei \& Lu 2014), and multi-million budget massively multiplayer online (MMO) games (Wang \& Wang 2008; Wu \& Holsapple 2014); and the bodies of literature on hedonic games and utilitarian games have thus far been disconnected. A large gap also exists between the purposes of games, i.e. between games for entertainment and those for instrumental purposes. This topic has been approached 
RUNNING TITLE: Why do people play games? A meta-analysis

from variety of theoretical perspectives, such as the technology acceptance model (Davis 1989), theory of reasoned action (Ajzen \& Fishbein 1980), and the uses and gratifications theory. Moreover, individual studies commonly investigate singular types of games and therefore typically have several issues that prevent a generalizability of their results such as their limited sample sizes or demographic biases. Moreover, almost no effort toward synthesizing this body of literature has yet been conducted. Therefore, in order to gain a comprehensive view of the multitude of factors explaining why people play or use games, an overview of the respective research is required. Although some game studies have been included in general technology acceptance meta-analyses (e.g. Schepers \& Wetzels 2007), no study has yet conducted a large scale analysis focusing specifically on the acceptance and use of game-related information systems.

In this study we aim to address this gap in our knowledge by mathematically meta-analyzing the quantitative literature that addresses the question of why people play/use games. Mathematical meta-analysis provides a highly accurate means of calculating the reasons and motivations why people use games across differing theoretical approaches and contexts of study. Therefore, we are not restricted by theoretical assumptions which stem from any specific theoretical frameworks. We examine the correlations between variables regardless of whether the analyzed studies had modelled a relationship between them. The primary objective of the study is to rigorously synthesize, validate and repeat those studies done on the question of why people play and use games. Therefore, our study not only presents highly reliable results on the topic, but is also able to take into account the relationships between variables that are not disclosed in the results of prior literature. Moreover, we also conduct structural equation modeling, based on the meta-analytically pooled correlations (MetaSEM, Cheung 2015) to examine the use of games 
RUNNING TITLE: Why do people play games? A meta-analysis

from a viewpoint of a technology acceptance model which has proved the most central theoretical perspective seen in the body of related literature.

Analyzing such a wide body of literature allows us to see the phenomenon from a wider perspective, and therefore the study is not limited by the narrow scope that singular studies are obliged to adopt. In this way, this study is able to derive larger theoretical implications pertaining to the positioning and understanding of games as information systems. Furthermore, by collating the studies, it is possible to lay a reliable foundation for the area of game use motivations, as well as the theoretical framing of games. As such, this study acts as a reference point for future studies that look to develop the area of games research.

\section{METHODS \& PROCEDURE}

The procedure began by gathering empirical studies related to game usage from academic literature repositories. A systematic search was conducted with a comprehensive combination of keywords, as well as a determination of clear inclusion criteria for the studies. Systematic review processes result in straightforward search, with a low ambiguity in the inclusion of studies and the details needed for a replicable review process, as well as a transparent methodology (Boell \& Cecez-Kecmanovic 2014; Oates 2015). After the elimination of unsuitable search hits, selected details were coded from the remaining set of valid studies. This step included the identification and combination of variables with similar definitions. The frequencies of the details are reported in the next section to provide an overview of the study of game usage. The meta-analytic approach is discussed at the end of this section. The process is visualized in Figure 1. 
RUNNING TITLE: Why do people play games? A meta-analysis

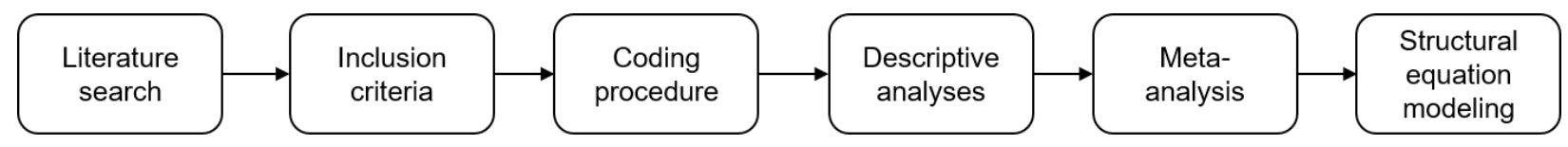

Figure 1: Analysis procedure workflow.

\subsection{Sources of data}

Following Webster and Watson (2002) and Ellis (2010), the analysis procedure commenced with a literature search. The search procedure was undertaken in the Scopus database (November 2015) which is the largest abstract and citation database of scholarly literature (Elsevier B.V 2014). Scopus is also the most relevant repository for studies within the disciplines where literature on why people adopt and use different technologies is being published. Among many others, Scopus also includes the AIS, ACM, IEEE and Science Direct libraries.

The literature search in Scopus was conducted using a search string which consisted of three main parts: 1) use-related keywords, 2) game-related keywords and 3) subject area specifications. We decided to exclude natural and medical sciences as these areas led to hundreds of false positives. As articles may have multiple subject areas in Scopus, excluding these areas only omits papers that are limited to these subjects. The search was targeted to the meta-data of papers (title, abstract and keywords) rather than the entire text and resulted in 985 entries. The complete search string is available in the appendix A.

\subsection{Inclusion criteria}

Eight inclusion criteria were used to assess the mass of research (985 entries) found by the

literature search. The inclusion procedure resulted in 48 valid research articles for meta-analysis. The inclusion process in visualized in Figure 2. 
RUNNING TITLE: Why do people play games? A meta-analysis

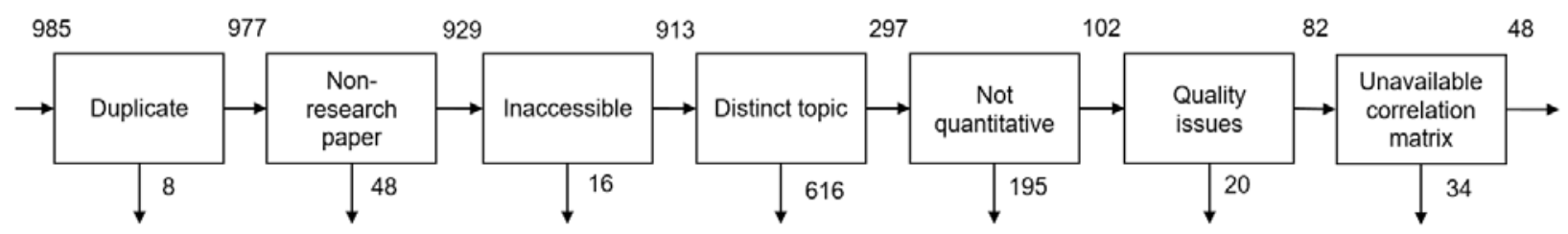

Figure 2: Inclusion criteria for research articles. Vertical arrows represent omitted research articles at each step while horizontal arrows show the remaining articles.

First, the studies were simply inspected as to whether they were duplicates. Eight research articles were omitted for sharing same results or data with more recent and extended versions of these papers that were already included.

Second, 48 entries were omitted since they were not full paper that had been published either in peer-reviewed journals, conferences or books.

Thirdly, due to inaccessibility, 16 entries were omitted. This category included entries with broken links and that could not be found via other methods, documents that were not accessible with our license. The accessibility check was undertaken as the third step since further inclusion criteria required closer examination of the actual contents of the papers.

Fourthly, the entries were inspected as to whether their topic or research question concerned the use of games. Inevitably, this was the largest omission category with 616 rejected search hits. In practice, any paper that was about adoption, technology acceptance, use, play, loyalty and continued use in context of the personal use of games satisfied this inclusion criterion. Some of these search hits were found because their topic related to techniques that are also used in games, they were about virtual worlds, or their abstract included games while the topic itself did not. 
RUNNING TITLE: Why do people play games? A meta-analysis

As a fifth step, the remaining entries were inspected for whether they included a quantitative empirical study. On this basis, 195 entries were omitted since the meta-analysis required actual measures from empirical studies with a similar research problem.

Next, we ensured that the studies met our quality expectations. Although we avoided being too restrictive in the quality evaluation, we required that the included studies should report essential information such as variable definitions and sampling processes with reasonable accuracy. However, 20 study articles were omitted from our analysis for reasons of insufficiently reported results, ambiguous variable definitions, and unclear study methodology.

Finally, and most pertinently to the meta-analysis calculations, the studies had to report correlations between their variables. A total of 34 studies were omitted for not reporting a valid correlation matrix. Most of these omitted papers did not report any matrix at all, a few reported only correlations between low level survey-items, and a single study clearly violated the criteria for validity and was therefore rejected.

After the inclusion process, a total of 48 studies were eligible for inclusion in the analyses.

\subsection{Coding procedure}

The analysis of the selected studies followed a two-stage process, and was conducted in accordance with the guidelines of Webster \& Watson (2002). The first step of the literature review framework is an author-centric analysis in which studies are listed in a table and selected details from the papers are entered in columns. For this review, the details included 1) the reference, 2) the context of the study (the game type and the actual game if disclosed in the study) 3) data collection and analysis methods, 4) sample size, 5) the variable correlation matrix, 
RUNNING TITLE: Why do people play games? A meta-analysis

and 6) the underlying theoretical framework of the study. The second stage of the literature review framework is a concept-centric approach (Webster \& Watson 2002). In this step, the author-centric analysis was pivoted and coded (with some abstraction to connect related papers under a given category) into concept-centric frequency tables. These tables are reported in the results section.

\subsection{1. $\quad$ Coding decisions}

The theoretical framework of the study refers to the basis of the research model used. It was decided to code the theoretical frameworks with a single value. In other words, studies which combine different theories are treated as different entries in the coding. This means that the sum of frequencies seen in the theoretical frameworks equals the number of studies in this review.

The literature review revealed a wide variety of different game types. However, not all games are solely entertainment products and games are increasingly being utilized to motivate the use of information systems which are designed for mainly utilitarian purposes (Hamari \& Koivisto 2015). For example, educational games use game elements to motivate their use, even though the ultimate goal is to learn school subjects. While the majority of the studies in the literature examined leisure-oriented commercial games, a noticeable portion of them were interested in games for instrumental purposes. Since these two game types are relatively different, we identified and categorized games into separate categories of hedonic and utilitarian games.

\subsection{2. $\quad$ Combining variables}

Since our meta-analysis combines variables across the studies, we had to pay extra attention when we coded the variable names. Inevitably, some studies used different terminology for 
RUNNING TITLE: Why do people play games? A meta-analysis

similar variables, as well as using the same names to describe relatively different concepts. Moreover, even when the studies measured similar variables, they rarely used an identical set of questions to construct their variables. Regardless of this, we combined and separated the variables accordingly, using a reasonable level of abstraction. In the end, by carefully combining similar concepts with varying details, we were able to extend our results across a larger scale.

\subsection{Meta-analytic approach}

Reviewing published research can be divided into two overall approaches: 1) traditional qualitative method (also known as the narrative method) in which the conclusions of reviewed studies are practically summarized using words, and 2) meta-analysis which is a mathematical and quantitative approach, and where the effect sizes of the reviewed studies are combined using calculations (Ellis 2010). The narrative approach has been found to be insufficient when synthesizing findings from contradictory results, especially for a large number of studies (Hunter \& Schmidt 2004), whereas the meta-analytic approach provides more comprehensive results with estimates for effect size, different metrics for reliability, and information about different kinds of bias. Moreover, unlike the narrative approach, meta-analysis does not suffer from increased complexity in interpreting large amounts of studies. Instead, meta-analysis addresses the discrete limitations of individual studies and settles conflicting findings (Paré et al. 2015). As the limitations of traditional narrative review are acknowledged, it is reasonable to employ a metaanalysis in this particular study. 
RUNNING TITLE: Why do people play games? A meta-analysis

\subsection{1. $\quad$ Meta-analysis calculation model}

More specifically, meta-analysis is a mathematical and statistical method for combining the results of previous studies that address a similar research problem (or the data/results which can be used to address a similar research problem) (Glass 1981). There are two main approaches for mathematical meta-analysis (Hunter \& Schmidt 2004; Ellis 2010): one developed by Hunter and Schmidt (Hunter \& Schmidt 2000; Schmidt \& Hunter 1977) and the other by Hedges et al. (Hedges 1981; Hedges 1992; Hedges \& Olkin 1985; Hedges \& Vevea 1998). In the approach of Hedges et al., raw correlations are z-transformed before combining the effects, and weights of $n$ - 3 are used instead of the original sample size (n) for each study. In contrast, the method by Hunter and Schmidt uses untransformed correlations, and the original sample size of each study. However, an analysis using this approach should modify the weights to be taken into account and correct the study-specific faults such as measurement reliability. The calculation of Hedges et al.'s random effect model uses the between-studies variance (Ellis 2010). These two approaches will likely produce slightly different mean effect sizes and intervals, but it is difficult to say which one is better overall as the differences are minor (Ellis 2010). For example, Field (2005) ended up with results contradictory to a similar study of Hall \& Brannick (2002), even though both employed the two methods in similar conditions using Monte Carlo simulations. However, Johnson et al. (1995) compared extensively different meta-analytic approaches and concluded that the Hunter \& Schmidt method produces differing results and should be used with caution. Although Schmidt \& Hunter (1999) later argued that this difference was caused by use of an inappropriate formula for error correction, we were more confident with the method of Hedges et al. and it was chosen as an approach for the purposes of this analysis. 
RUNNING TITLE: Why do people play games? A meta-analysis

Both meta-analytic calculation approaches include at least two different models, namely to account for fixed and random effects. In principle, a fixed effects model should be used when the studies share identical data collection conditions and a single value for the true effect is assumed. Thus, using a fixed effect generally produces less variance as well as tighter confidence intervals. On the other hand, a random effects model should be used when the study conditions are expected to vary, and the distribution for the true effect is assumed. Indeed, in most real life scenarios and meta-analyses, it would be absurd to assume that identical study conditions exist between studies. Moreover, as our data clearly suggests dissimilar conditions with varying variable details as well as different cultures and demographics amongst the respondents, it is reasonable to employ a random effects meta-analysis. Therefore, we used the approach of Hedges et al., and a random effects model in our meta-analysis. The calculation formulas used in our meta-analysis are available in appendix D.

\subsection{2. $\quad$ Test of heterogeneity}

Despite the assumption that a random effect basis is preferred to a fixed effects model when combining the effect sizes of independent studies, we verified our model approach using tests for heterogeneity. The heterogeneity of our data was tested with Q-statistics and $\mathrm{I}^{2}$-values for every relationship that was analyzed in meta-analysis (these heterogeneity tests are available in appendix B). The Q-statistic (Cochran 1954) is the classical measure for heterogeneity while the $\mathrm{I}^{2}$-value represents the percent of the variance explained by the heterogeneity of the data, and the minimum of $0 \%$ indicates that all variability is instead due to sampling error within trials (Higgins \& Thompson 2002). All Q-estimates were statistically significant at $\mathrm{p}<0.01$ and each 
RUNNING TITLE: Why do people play games? A meta-analysis

$\mathrm{I}^{2}$-value was above $80 \%$ (mostly above $90 \%$ ). Thus, the random effect model is seen as a proper approach for conducting this particular meta-analysis.

\subsubsection{Effect interpretation \& publication bias}

Correlation effect sizes were interpreted using Cohen’s (1988) small, medium and large thresholds, and therefore the three classes for interpreting effect sizes were:

- $\quad$ Small (S) for values between $0.10-0.30$

- $\quad$ Medium (M) for values between 0.30 - 0.50

- $\quad$ Large (L) for values between 0.50 - 1.00

To address the problem of publication bias, failsafe $\mathrm{N}$ was calculated for each of the analyzed relationships. The fundamental concept is to determine the number of additional studies with zero result needed to nullify an effect. There are two main approaches for such calculations (Long 2001): one method based on the sum of the Z scores (Rosenthal 1979) while the other uses effect sizes (Orwin 1983). The latter was used in this analysis since it provides more accurate results without the need for an interpretation of statistical significance testing (Long 2001). Additionally, the method collaborates well with the classes for effect sizes featured in this study. We used the small-threshold as criterion value for fail-safe studies, and zero for the mean effect size of the fail-safe studies (Eq. 1).

$$
\text { Failsafe } N=\frac{k(r-0.1)}{0.1}
$$

Where $\mathrm{k}$ is the number of studies in the analysis, $\mathrm{r}$ is the mean effect size, and value 0.1 (the small effect size threshold) is the criterion value for failsafe studies. A higher failsafe $\mathrm{N}$ value 
RUNNING TITLE: Why do people play games? A meta-analysis

implies a more reliable result in the aspect of publication bias. For interpretation of the value, the failsafe $\mathrm{N}$ / $\mathrm{k}$-ratio should exceed the threshold of 2.0, otherwise publication bias might pose a potential problem (Sabherwal et al. 2006).

\subsubsection{Moderator analysis tests}

The purpose of our moderator analysis is to examine the difference in meta-analysis results between two different types of games. The difference between the two correlation estimates is examined by way of Q-test, which tests the homogeneity and significance of variance between groups (Borenstein et al. 2009). Similar to actual meta-analysis, the test also requires some decisions regarding the calculation model to be used. First, one must choose between a fixed or random effect model, depending on how the within group estimates are to be calculated. Similar to the main meta-analysis, we had no reason to believe that even studies within the same game categories would have such identical research conditions, that a fixed effect could be assumed. Therefore, the subgroup estimates are calculated using a random effects model. As a second issue, one must decide whether to assume true between-studies variance for both subgroups or to estimate separate variances. However, a relatively low number of studies within subgroups does not allow for the separate variances for each group to be estimated with any reasonable accuracy. On the other hand, we had no reason to assume different variances for these groups, so the same within studies estimate for variance is used for both subgroups.

\subsection{Meta-analytic structural equation modeling}

In addition to our correlation based meta-analysis, we used structural equation modeling to further investigate the effectiveness of a technology acceptance model in explaining the use 
RUNNING TITLE: Why do people play games? A meta-analysis

intention of games. We used AMOS v23 to test our models and used correlation matrixes which were constructed from our meta-analysis results as an input to the software (available in appendix C). However, while structural equation models are often used with raw questionnaire data, using a meta-analytically pooled correlation matrix as data is relatively uncommon, and thus we were required to address some differences between these methods.

First, we had to decide which sample size to use for the correlation matrix, given that the relationships for the meta-analysis were gathered from a variety of studies and the total sample sizes varied from 1670 to 13116 for individual relationships. However, researchers have previously used medians, totals, arithmetic and harmonic means (Cheung 2015), as well as minimums (Schepers \& Wetzels 2007) of meta-analysis sample sizes. Based on recommendations offered in literature (Landis 2013), we decided to use the harmonic mean.

Next, using a correlation matrix as data input in structural equation modeling requires estimates of the standard deviation of the variables. While it could have been possible to estimate the standard deviation for each variable (e.g. by weighted averaging deviation drawn from each study), it would have reduced our sample size significantly. Most of the included studies did not report standard deviations, so requiring these measurements as part of our inclusion criteria would have unnecessarily caused many articles to be omitted from our analysis. On the other hand, most meta-analysis studies tend to treat correlation matrix as a covariance matrix in structural equation modeling (Cheung 2015) and thus avoid estimating the standard deviations. In line with this literature and according to our own evaluation, we also decided to treat correlation matrix as a covariance matrix by using unit standard deviations. 
RUNNING TITLE: Why do people play games? A meta-analysis

\section{3. $\quad$ RESULTS}

\subsection{Descriptive information of the analyzed literature}

The search process resulted in 48 relevant research articles for inclusion in the analysis (listed in Table 1 in ascending alphabetical order of the reference). Overall, the sample sizes varied from 32 to 3919, with a mean of 524 and a standard deviation of 698. The articles had been published between the years 2004 and 2015. 41 of the studies were published in journals, while the remaining 7 were conference papers. 
RUNNING TITLE: Why do people play games? A meta-analysis

Table 1: Included studies in the analysis.

\begin{tabular}{|c|c|c|c|}
\hline Study reference & $\mathrm{n}$ & Game type & Venue \\
\hline Bourgonjon et al. (2010) & 858 & Utilitarian & Computers \& Education \\
\hline Chang (2013) & 358 & Hedonic & Telematics \& Informatics \\
\hline Chang et al. (2014) & 166 & Hedonic & Internet Research \\
\hline Chen \& Kuan (2012) & 610 & Hedonic & International Journal of Mobile Communications \\
\hline Cheng et al. (2013) & 32 & Utilitarian & Australasian Journal of Educational Technology \\
\hline \multirow[t]{2}{*}{ Hamari (2015) } & 389 & Hedonic & International Journal of Information Management \\
\hline & 237 & Hedonic & \\
\hline Hamari \& Koivisto (2015) & 200 & Utilitarian & International Journal of Information Management \\
\hline Hartmann et al. (2012) & 351 & Hedonic & Journal of Media Psychology \\
\hline Hong et al. (2011) & 112 & Utilitarian & Turkish Online Journal of Educational Technology \\
\hline Hsiao \& Chiou (2012) & 347 & Hedonic & Electronic Commerce Research \& Applications \\
\hline Hsiao \& Chiou (2012) & 347 & Hedonic & Information \& Management \\
\hline Hsu \& Lu (2004) & 233 & Hedonic & Information \& Management \\
\hline Huang \& Hsieh (2011) & 251 & Hedonic & Internet Research \\
\hline Hwang et al. (2013) & 224 & Utilitarian & Computers \& Education \\
\hline Jung et al. (2014) & 246 & Hedonic & Journal of Business Research \\
\hline Kari \& Makkonen (2014) & 271 & Utilitarian & International conference on Information Systems \\
\hline Kim et al. (2014) & 213 & Utilitarian & Services Marketing Quarterly \\
\hline Koo (2009) & 576 & Hedonic & Computers in Human Behavior \\
\hline Kuo et al. (2011) & 60 & Utilitarian & Edutainment Technologies \\
\hline Laumer et al. (2012) & 1882 & Utilitarian & German Journal of Research in Human Resource Management \\
\hline Lee (2009) & 628 & Hedonic & Online Information Review \\
\hline Li et al. (2015) & 3919 & Hedonic & Computers in Human Behavior \\
\hline Liu \& Li (2011) & 267 & Hedonic & Computers in Human Behavior \\
\hline Lu \& Wang (2008) & 1186 & Hedonic & Internet Research \\
\hline Naeini \& BalaKrishnam (2012) & 201 & Hedonic & Journal of Applied Sciences, Engineering \& Technology \\
\hline Okazaki et al. (2008) & 432 & Hedonic & Journal of Computer Mediated Communication \\
\hline Park et al. (2014) & 1409 & Hedonic & Telematics \& Informatics \\
\hline Petrova \& Qu (2007) & 96 & Hedonic & International Conference on e-Business \\
\hline Shin $(2010)$ & 312 & Hedonic & International Journal of Human-Computers Interaction \\
\hline Shin \& Shin (2011) & 280 & Hedonic & Computers in Human Behavior \\
\hline Sun \& Law (2010) & 115 & Utilitarian & Transactions on Edutainment \\
\hline Tao et al. (2009) & 185 & Utilitarian & Computers \& Education \\
\hline Teng (2010) & 865 & Hedonic & Computers in Human Behavior \\
\hline Teng (2013) & 2861 & Hedonic & Cyberpsychology, Behavior \& Social Networking \\
\hline Teng \& Chen (2014) & 546 & Hedonic & Electronic Commerce Research \& Applications \\
\hline Teng et al. (2012) & 994 & Hedonic & Journal of Computer-Mediated Communication \\
\hline Teng et al. (2012) & 767 & Hedonic & Online Information Review \\
\hline Tu \& Hung (2010) & 307 & Hedonic & PICMET \\
\hline Wang (2014) & 411 & Hedonic & Computers in Human Behavior \\
\hline Wang \& Wang (2008) & 281 & Hedonic & British Journal of Educational Technology \\
\hline Wei \& Lu (2014) & 237 & Hedonic & Internet Research \\
\hline Wu \& Holsapple (2014) & 443 & Hedonic & Information \& Management \\
\hline Wu \& Li (2007) & 253 & Hedonic & Americas Conference on Information Systems \\
\hline Wu et al. (2010) & 337 & Hedonic & Computers in Human Behavior \\
\hline Yoon et al. (2013) & 244 & Hedonic & Journal of Applied Social Psychology \\
\hline Zhang et al. (2010) & 109 & Hedonic & Journal of Information \& Computational Science \\
\hline Zhao \& Fang (2009) & 315 & Hedonic & Internationalization, Design and Global Development \\
\hline Zhou (2013) & 231 & Hedonic & Personal \& Ubiquitous Computing \\
\hline
\end{tabular}

$n=$ sample size. 
RUNNING TITLE: Why do people play games? A meta-analysis

The theoretical basis of the reviewed studies was also examined. The theoretical frameworks which determine the structure of the research models used by the studies are listed in Table 2. However, rather a high amount of studies (12) used no specific theoretical framework explicitly, and instead the variables were adopted from various theories, different studies, or were created by the authors. The technology acceptance model (Davis et al. 1989) (TAM) was the most used, and was a feature in 15 studies. When combining this with less frequently used combinations of the model, we get a total of 23 research models that were based on TAM. The second most common theory was the Uses \& Gratifications Theory and the Theory of Reasoned Action (Ajzen \& Fishbein 1980) (TRA) which were used in 4 and 3 studies respectively. However, together with the theoretical combinations, 11 studies had TRA as part of their theoretical foundation. TAM is actually one of the most widely used extensions of TRA and they share some common variables and relationships. The theory of planned behavior (Ajzen 1991) is another extension of TRA and was used by 4 studies as the theoretical basis (and featured exclusively in 3 of these). The remainder of the theoretical frameworks were less used, or featured rarely seen combinations.

Table 2: Frequency of theoretical frameworks in the analyzed literature.

\begin{tabular}{ll}
\hline Theoretical Framework & $\mathrm{k}$ \\
\hline TAM & 15 \\
Various theories & 12 \\
TAM + TRA & 7 \\
Uses \& Gratifications Theory & 4 \\
TRA & 3 \\
TPB & 3 \\
Social Capital Theory & 2 \\
TAM + TRA + TPB & 1 \\
\hline k= number of studies. TAM = technology acceptance model, TRA = theory of reasoned action, TBP = theory of planned behavior.
\end{tabular}


RUNNING TITLE: Why do people play games? A meta-analysis

\subsection{Variables}

Since the data contains 758 unique correlation pairs, the scope of analysis must be limited. As a statistical method, meta-analysis prefers multiple findings for establishing relationships and therefore it is reasonable to only include the most frequently studied correlations in the analysis. Thus, we focused on variables that were included in at least three independent studies. These variables are briefly introduced in Table 3.

Table 3: Most frequently investigated variables in the analyzed literature.

\begin{tabular}{|c|c|c|}
\hline Variable & k & Description \\
\hline $\begin{array}{l}\text { Playing Intention } \\
\text { (INT) }\end{array}$ & 41 & $\begin{array}{l}\text { Intention to behave in a certain way (Ajzen \& Fishbein 1980). In context of games, it is more specifically } \\
\text { future intention to play games, to continue playing games, to continue playing specific. }\end{array}$ \\
\hline Enjoyment (ENJ) & 24 & $\begin{array}{l}\text { User perception of how enjoyable, entertaining and fun playing games or specific game is (Davis et al. } \\
\text { 1992; Van der Heijden 2004). }\end{array}$ \\
\hline $\begin{array}{l}\text { Perceived Ease } \\
\text { of Use (PEOU) }\end{array}$ & 22 & $\begin{array}{l}\text { "The degree to which an individual believes that using a particular system would be free of physical and } \\
\text { mental effort" (Davis 1989). In context of games, ease of use particularly concerns the effortless in user } \\
\text { interface, such as playing games being easy to learn and sense of control when playing, neither than } \\
\text { difficulty level of games. }\end{array}$ \\
\hline Attitude (ATT) & 19 & $\begin{array}{l}\text { Attitude is own opinion on how positive or negative the actual behavior is (Ajzen \& Fishbein 1980). } \\
\text { Therefore, attitude towards using games includes opinion on whether playing games is good idea and } \\
\text { how much people like playing games. }\end{array}$ \\
\hline $\begin{array}{l}\text { Perceived } \\
\text { Usefulness (PU) }\end{array}$ & 18 & $\begin{array}{l}\text { "The degree to which an individual believes that using a particular system would enhance his or her job } \\
\text { performance" (Davis 1989). However in practice, perceived usefulness was defined loosely as any } \\
\text { sense of usefulness in playing games. }\end{array}$ \\
\hline $\begin{array}{l}\text { Subjective } \\
\text { Norms (SN) }\end{array}$ & 14 & $\begin{array}{l}\text { Perceived social pressure from other people on how acceptable the activity (use of games) is (Ajzen \& } \\
\text { Fishbein 1980). Also often referred as "social norms" or "social influence". }\end{array}$ \\
\hline Flow & 8 & $\begin{array}{l}\text { Flow is a mental state where a person is fully immersed, deeply concentrated and truly enjoys while } \\
\text { performing a certain activity (Csikszentmihalyi 1990). Flow is the optimal experience in use of games } \\
\text { and may lead to ignoring real world surroundings while playing. }\end{array}$ \\
\hline $\begin{array}{l}\text { Perceived } \\
\text { Playfulness (PP) }\end{array}$ & 6 & $\begin{array}{l}\text { Perception on how focused one is, degree of curiosity and how enjoyable or interesting it is when } \\
\text { interacting with games (Moon \& Kim 2001; Webster \& Martocchio 1992) Playfulness is conceptually } \\
\text { rather similar to enjoyment and flow. }\end{array}$ \\
\hline
\end{tabular}


RUNNING TITLE: Why do people play games? A meta-analysis

\begin{tabular}{|l|l|l|}
\hline $\begin{array}{l}\text { Satisfaction } \\
\text { (SAT) }\end{array}$ & 6 & $\begin{array}{l}\text { Satisfaction is the positive feeling that arises from how well the actual experience meets expected } \\
\text { experience (Bhattacherjee 2001; Hernon \& Whitman 2001). }\end{array}$ \\
\hline $\begin{array}{l}\text { Critical Mass } \\
\text { (CM) }\end{array}$ & 3 & User perception on amount of peers that are also playing games or a specific game. \\
\hline Gender & 3 & Binary variable for gender of the respondent. Positive sign in correlation represents males. \\
\hline
\end{tabular}

\subsection{Meta-analysis}

\subsection{1. $\quad$ Main findings}

The meta-analysis results for the most frequently studied variables are available in Table 4 and in Figure 3 in descending order of their correlation strength. Among the variables that correlate directly with playing intention, Attitude has clearly the strongest relationship (0.689***). Enjoyment $\left(0.586^{* * *}\right)$ and Perceived Usefulness $\left(0.572^{* * *}\right)$ also reach the large correlation class. Moreover, correlations for Satisfaction, Perceived Ease of Use, as well as Perceived Playfulness are categorized as medium in their strength $\left(0.473^{*}, 0.438 * * *\right.$, and $0.435^{* * *}$, respectively). Subjective Norms, Critical Mass, and Flow also reach the medium correlation category $\left(0.391^{* * *}, 0.381^{* *}\right.$, and $0.373^{* * *}$, respectively). However, the meta-analysis could not detect a connection between Gender and Playing Intention $\left(-0.055^{\text {ns }}\right)$. 
RUNNING TITLE: Why do people play games? A meta-analysis

Table 4: Meta-analysis of correlations between most frequently examined variables.

\begin{tabular}{|c|c|c|c|c|c|c|c|c|c|c|}
\hline \multirow[b]{2}{*}{ Variables } & \multirow[b]{2}{*}{$\mathrm{k}$} & \multirow[b]{2}{*}{$\sum n$} & \multirow[b]{2}{*}{$\mathrm{C}$} & \multirow[b]{2}{*}{ r } & \multicolumn{2}{|c|}{ 95\% conf. int. } & \multirow[b]{2}{*}{ z } & \multirow[b]{2}{*}{$\mathrm{p}$} & \multirow[b]{2}{*}{ fsN } & \multirow{2}{*}{$\begin{array}{l}\text { p. bias } \\
\text { risk }\end{array}$} \\
\hline & & & & & Low & High & & & & \\
\hline \multicolumn{11}{|c|}{ Correlations with playing intention } \\
\hline INT x ATT & 19 & 6209 & $\mathrm{~L}$ & $0.689 * * *$ & 0.626 & 0.743 & 14.939 & 0.000 & 112 & Low \\
\hline INT $x$ ENJ & 22 & 13116 & $\mathrm{~L}$ & $0.586^{\star * *}$ & 0.517 & 0.648 & 13.256 & 0.000 & 108 & Low \\
\hline INT x PU & 17 & 7207 & $\mathrm{~L}$ & $0.572^{\star * *}$ & 0.469 & 0.659 & 9.039 & 0.000 & 81 & Low \\
\hline INT x SAT & 3 & 1952 & M & $0.473^{*}$ & 0.110 & 0.725 & 2.495 & 0.013 & 12 & Low \\
\hline INT $\times$ PEOU & 21 & 8332 & M & $0.438^{* * *}$ & 0.351 & 0.518 & 8.929 & 0.000 & 72 & Low \\
\hline INT x PP & 5 & 1389 & $M$ & $0.435^{\star \star *}$ & 0.282 & 0.566 & 5.188 & 0.000 & 17 & Low \\
\hline INT $x$ SN & 14 & 3979 & $M$ & $0.391^{* \star *}$ & 0.296 & 0.479 & 7.517 & 0.000 & 41 & Low \\
\hline INT x CM & 3 & 643 & $M$ & $0.381^{\star *}$ & 0.158 & 0.567 & 3.258 & 0.001 & 9 & Low \\
\hline INT x Flow & 7 & 2208 & $M$ & $0.373^{\star * *}$ & 0.252 & 0.482 & 5.733 & 0.000 & 20 & Low \\
\hline INT x GEN & 3 & 339 & - & $-0.055^{\mathrm{ns}}$ & -0.315 & 0.213 & -0.395 & 0.693 & -5 & High \\
\hline \multicolumn{11}{|c|}{ Correlations between other variables } \\
\hline ATT $x$ PU & 10 & 3517 & $\mathrm{~L}$ & $0.641^{\star \star *}$ & 0.485 & 0.757 & 6.491 & 0.000 & 55 & Low \\
\hline ATT $\times$ ENJ & 11 & 4643 & $\mathrm{~L}$ & $0.596^{\star \star *}$ & 0.535 & 0.650 & 15.124 & 0.000 & 55 & Low \\
\hline ENJ x PU & 9 & 5519 & $\mathrm{~L}$ & $0.562^{* * *}$ & 0.420 & 0.676 & 6.654 & 0.000 & 42 & Low \\
\hline PEOU X PU & 15 & 6848 & M & $0.493^{\star \star *}$ & 0.350 & 0.614 & 6.049 & 0.000 & 59 & Low \\
\hline ENJ $\times$ PEOU & 12 & 6400 & M & $0.437^{\star * *}$ & 0.320 & 0.541 & 6.721 & 0.000 & 41 & Low \\
\hline ATT $x$ PEOU & 12 & 4049 & $M$ & $0.432^{\star \star *}$ & 0.316 & 0.534 & 6.745 & 0.000 & 40 & Low \\
\hline $\mathrm{SN} \times \mathrm{ENJ}$ & 8 & 2588 & $M$ & $0.413^{\star * *}$ & 0.277 & 0.533 & 5.564 & 0.000 & 26 & Low \\
\hline $\mathrm{SN} \times \mathrm{ATT}$ & 9 & 2728 & $M$ & $0.398^{* \star *}$ & 0.280 & 0.505 & 6.178 & 0.000 & 27 & Low \\
\hline $\mathrm{SN} \times \mathrm{PU}$ & 5 & 1670 & M & $0.336^{\star \star}$ & 0.121 & 0.521 & 2.999 & 0.003 & 12 & Low \\
\hline SN $\times$ PEOU & 8 & 2430 & $\mathrm{~S}$ & $0.205^{\star \star \star}$ & 0.121 & 0.286 & 4.713 & 0.000 & 9 & High \\
\hline
\end{tabular}

The meta-analysis results also show several relationships beyond direct correlations with playing intention, which are especially important for the multi-level analyses presented in the next section. The results show strong correlations between the variables of Attitude, Enjoyment and Usefulness. The correlation between Attitude and Usefulness is the strongest $\left(0.641^{* * *}\right)$, and Attitude also has a considerably strong correlation with Enjoyment (0.596***). Quite interestingly, the results reveal that Enjoyment and Usefulness are strongly associated $\left(0.562^{* * *}\right)$. In addition, the results show 6 mediocre relationships which commonly involve 
either Ease of Use or Subjective Norms, with a single low correlation between these two variables $\left(0.205^{* * *}\right)$, which is the lowest estimate in our meta-analysis.

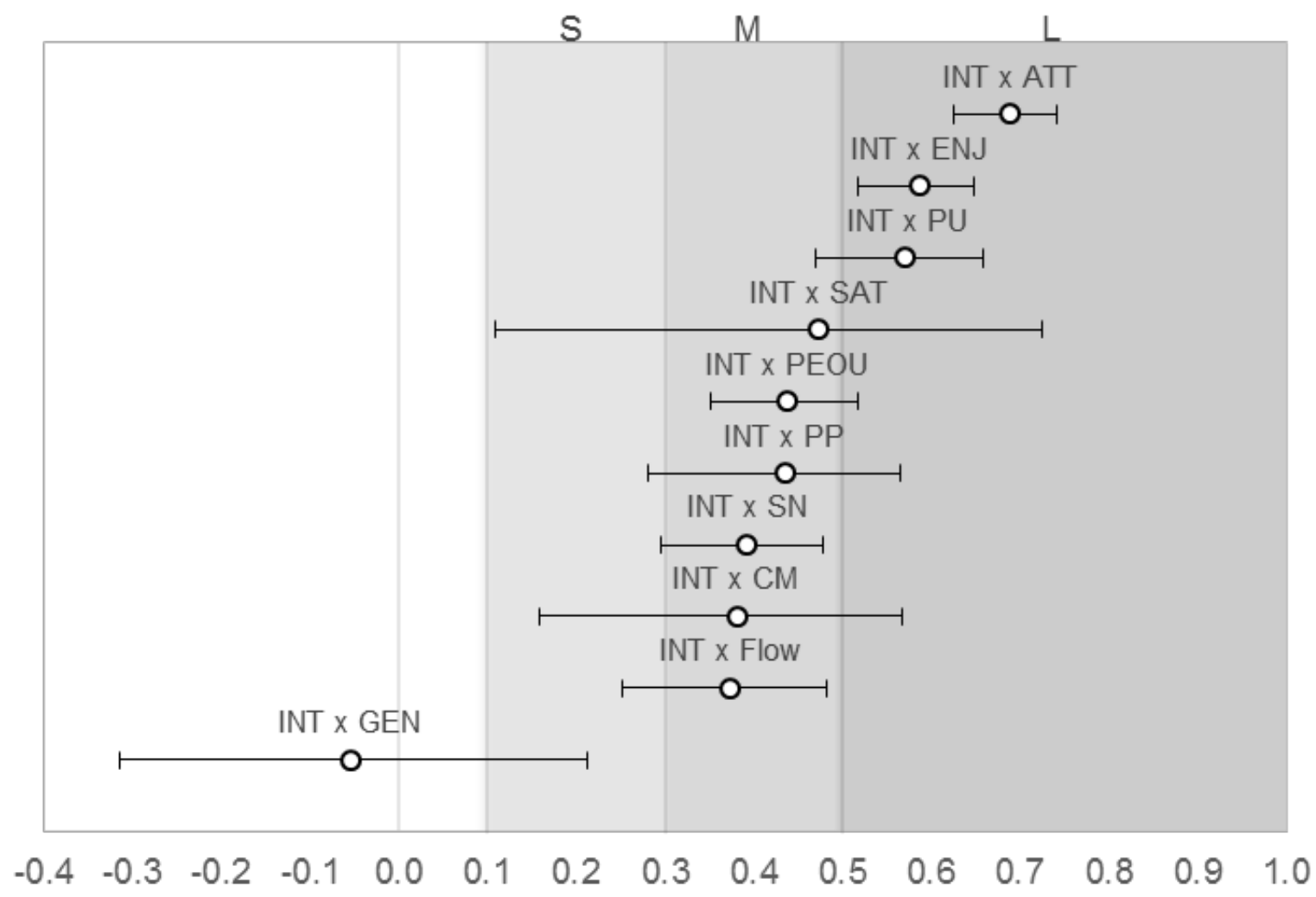

Figure 3: Meta-analysis of correlations between most frequently examined variables and playing intention. INT playing intention, ATT attitude toward playing games, ENJ enjoyment, PU perceived usefulness, SAT satisfaction, PEOU perceived ease of use, SN subjective norms, CM critical mass, GEN gender. S small, M medium, L large.

As can be seen from both Figure 3 and the result table, the correlation between playing intention and gender is the only non-significant estimate occurring in the meta-analysis. Moreover, this estimate has wide confidence intervals and thus the results do not show any signs of a connection between these variables. The results show an even wider confidence interval for the correlation between satisfaction and intention, although the estimate is significant and clearly positive. 
RUNNING TITLE: Why do people play games? A meta-analysis

Nevertheless, all other confidence intervals are rather narrow and most failsafe $\mathrm{N}$ measures indicate low risk of publication bias (Sabherwal et al. 2006).

\subsubsection{Moderating effect of game type}

We also tested differences between hedonic and utilitarian type of games by dividing the sample into two subgroups and comparing the correlations. For the sake of simplicity and interpretability, we limited the moderator analysis for variables with direct correlations with playing intention. According to the moderator analysis results (Table 5 and Figure 4), the game types differed most significantly $(\mathrm{Q}=55.988 * * *)$ in the correlation between Perceived Usefulness and Playing Intention, where hedonic games had a significantly lower estimate $\left(0.392^{* * *}\right)$ than utilitarian games $\left(0.724^{* * *}\right)$. Moreover, the estimates also varied significantly in the correlation for Perceived Ease of Use $\left(Q=17.953^{* * *}\right)$, where again hedonic games had a significantly lower correlation $\left(0.325^{* * *}\right)$ than utilitarian games $(0.550 * * *)$. The moderator analysis also detected a significant difference in the relationship between Playing Intention and Subjective Norms $\left(\mathrm{Q}=7.524^{* *}\right)$, although this difference is considerably lower than in the above-mentioned estimates. However, the analysis could not detect a significant difference for Attitude $\left(\mathrm{Q}=2.168^{\mathrm{ns}}\right)$ and Enjoyment $\left(\mathrm{Q}=0.030^{\mathrm{ns}}\right)$ between the game categories. 
RUNNING TITLE: Why do people play games? A meta-analysis

Table 5: Meta-analysis for difference in effects between hedonic and utilitarian games.

\begin{tabular}{|c|c|c|c|c|c|c|c|c|c|c|c|}
\hline \multirow[b]{2}{*}{ Variables } & \multirow[b]{2}{*}{ k } & \multirow[b]{2}{*}{$\sum n$} & \multirow[b]{2}{*}{ C } & \multirow[b]{2}{*}{$r$} & \multicolumn{2}{|c|}{ 95\% conf. int. } & \multirow[b]{2}{*}{ z } & \multirow[b]{2}{*}{$\mathrm{p}$} & \multirow[b]{2}{*}{ fsN } & \multicolumn{2}{|l|}{ Q-test } \\
\hline & & & & & Low & High & & & & $\mathrm{Q}$ & $P$ \\
\hline \multicolumn{12}{|l|}{$\mathrm{PU}$} \\
\hline Hedonic & 9 & 3766 & M & $0.392^{\star \star *}$ & 0.317 & 0.462 & 9.467 & 0.000 & 27 & $55.988^{\star \star \star}$ & 0.000 \\
\hline Utilitarian & 8 & 3441 & $\mathrm{~L}$ & $0.724^{\star \star *}$ & 0.673 & 0.768 & 18.036 & 0.000 & 50 & & \\
\hline \multicolumn{12}{|l|}{ PEOU } \\
\hline Hedonic & 11 & 4407 & M & $0.325^{\star \star \star}$ & 0.245 & 0.400 & 7.625 & 0.000 & 25 & $17.953^{\star \star \star}$ & 0.000 \\
\hline Utilitarian & 10 & 3925 & $\mathrm{~L}$ & $0.550^{\star \star *}$ & 0.479 & 0.614 & 12.513 & 0.000 & 45 & & \\
\hline \multicolumn{12}{|l|}{ SN } \\
\hline Hedonic & 11 & 3396 & M & $0.337^{\star \star \star}$ & 0.250 & 0.419 & 7.218 & 0.000 & 27 & $7.524^{\star *}$ & 0.006 \\
\hline Utilitarian & 3 & 583 & $\mathrm{~L}$ & $0.569 * \star *$ & 0.428 & 0.682 & 6.745 & 0.000 & 15 & & \\
\hline \multicolumn{12}{|l|}{ ATT } \\
\hline Hedonic & 13 & 5370 & L & $0.660^{\star \star *}$ & 0.579 & 0.728 & 11.798 & 0.000 & 73 & $2.168^{\text {ns }}$ & 0.141 \\
\hline Utilitarian & 4 & 839 & L & $0.751^{\star \star \star}$ & 0.647 & 0.827 & 9.323 & 0.000 & 27 & & \\
\hline \multicolumn{12}{|l|}{ ENJ } \\
\hline Hedonic & 18 & 10550 & L & $0.589 * \star \star$ & 0.507 & 0.661 & 11.306 & 0.000 & 89 & $0.030^{\text {ns }}$ & 0.862 \\
\hline Utilitarian & 4 & 2566 & $\mathrm{~L}$ & $0.573^{\star \star *}$ & 0.383 & 0.717 & 5.133 & 0.000 & 19 & & \\
\hline
\end{tabular}

Every estimate in the moderator analysis was rather strong and above the lower bound of the medium correlation class. Although there were only three studies examining the relationship between Subjective Norms and playing intention for utilitarian games, all our correlation estimates are statistically significant at $\mathrm{p}<0.001$, and all of the failsafe $\mathrm{N}$ values indicate only a low risk of publication bias. Thus, we determined that we could reliably interpret the comparison results. 


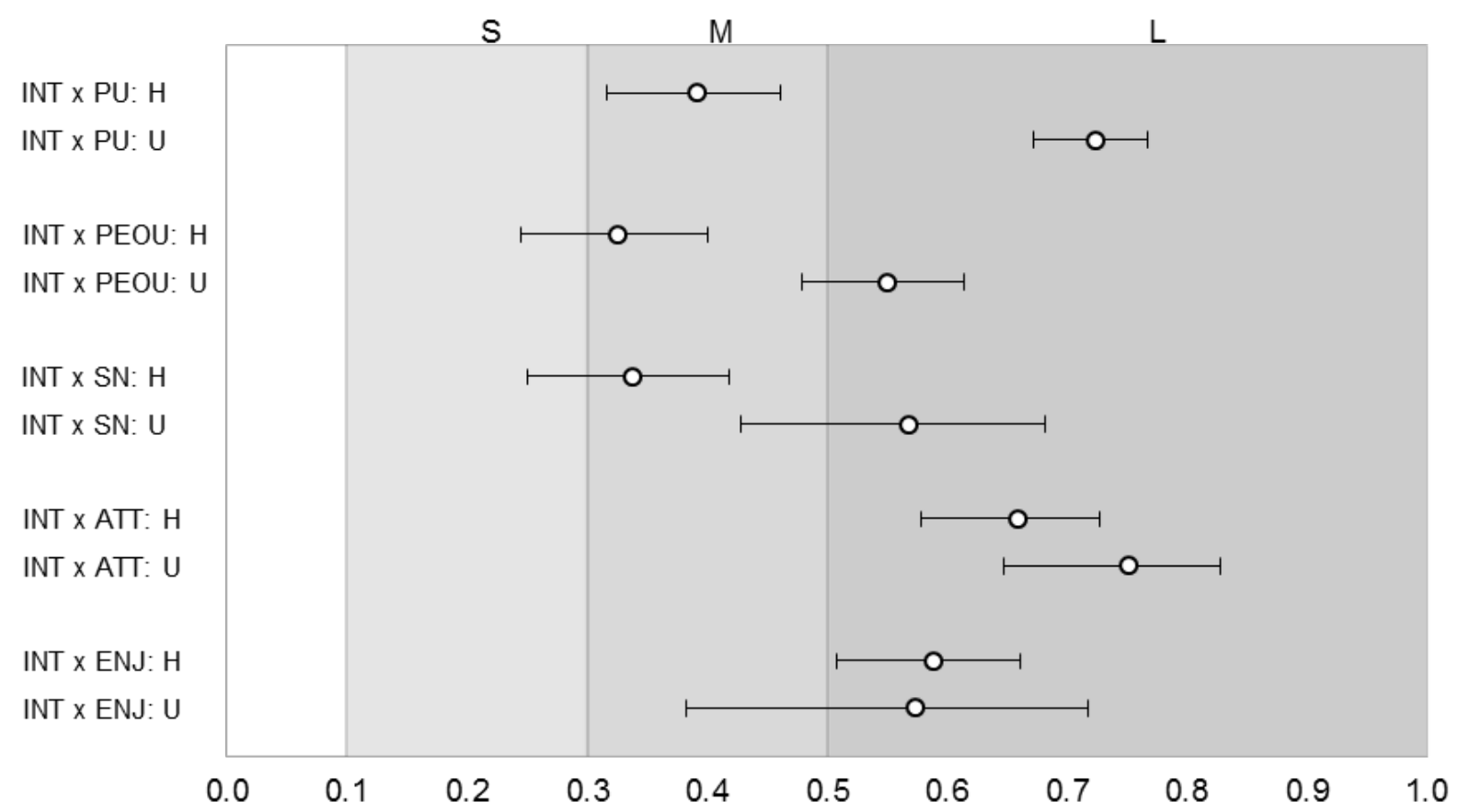

Figure 4: Meta-analysis for difference between hedonic and utilitarian games. INT playing intention, ATT attitude toward playing games, ENJ enjoyment, PU perceived usefulness, PEOU perceived ease of use, SN subjective norms. S small, M medium, L large. $H$ hedonic games, $U$ utilitarian games.

\subsection{Structural equation modeling}

\subsection{1. $\quad$ The overall model}

In meta-SEM (or any regression-based analysis), as the model structure is more complex and more variables are included simultaneously in the model, the set of studies that can be included diminishes from the correlation-based analyses (above) since all of the included studies have to feature all of the variables in the model. Our investigation shows that studies based on the Technology Acceptance Model are the only ones that can be feasibly modeled as a (meta-)SEMmodel. This was to be expected since the largest share of the studies had approached the research 
RUNNING TITLE: Why do people play games? A meta-analysis

problem from a technology acceptance perspective (Table 3), and/or by the inclusion of variables of usefulness, enjoyment, attitude and ease of use along the use-related dependent variable. This is commonly seen in studies that lean on the technology acceptance model. We employ the model structure introduced by Van der Heijden (2004) which extended the core TAM model with the inclusion of enjoyment (Figure 5) where enjoyment is treated as an equal predictor of use with usefulness: both predict use as well as the use of attitude.

The results of the structural equation model can be seen in Figure 5. The results show that playing intention is most strongly predicted by attitude $\left(0.455^{* * *}\right)$, whereas enjoyment and perceived usefulness have noticeably weaker, but still significant, direct relationships with intention $\left(0.231^{* * *}\right.$ and $0.151^{* * *}$ respectively). Moreover, both usefulness and enjoyment are similarly positively associated with attitude $\left(0.417^{* * *}\right.$ and $0.325^{* * *}$ respectively). Although the results show a significant association in the path from perceived ease of use to attitude $\left(0.084^{* * *}\right)$, its magnitude is the lowest in the analysis. Finally, perceived ease of use similarly has rather high coefficients for the paths between it and perceived usefulness $(0.493 * * *)$ and enjoyment $(0.437 * * *)$. 
RUNNING TITLE: Why do people play games? A meta-analysis

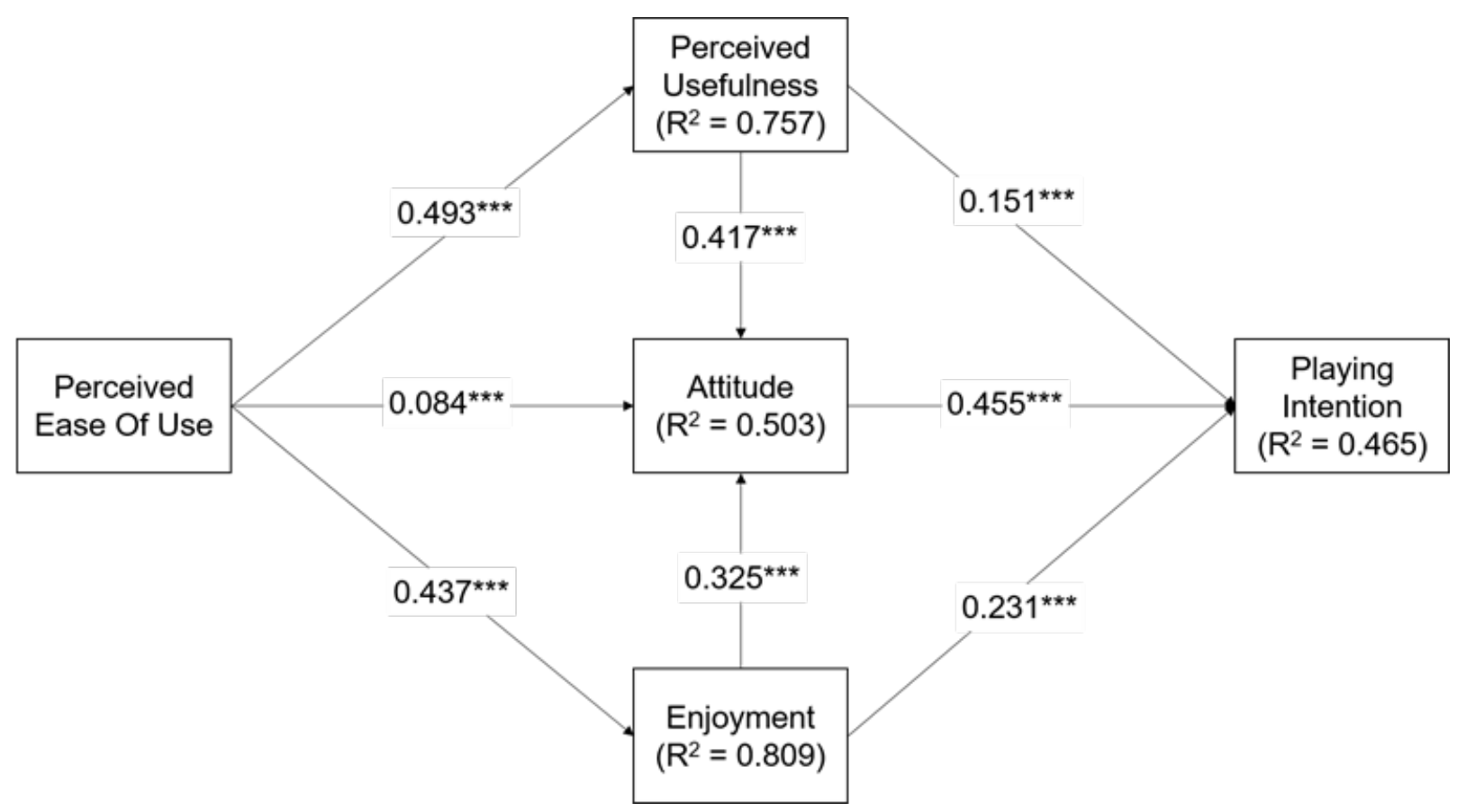

Figure 5: Results for structural equation modeling with total sample. ${ }^{* *} p<0.001,{ }^{* *} p<0.01$, * $p<0.05,{ }^{n s} p>0.05 . R^{2}$ total variance explained.

The structural equation modeling results seem to roughly replicate the themes that were raised in the results of non-SEM meta-analysis (Table 4): if we look at games as a whole, all the main factors of the technology acceptance model are important predictors of playing games. At the same time however, the results also lend support for our hypothesis (discussed from the outset of the study) that it does not seem meaningful to place the whole spectrum of games under one category. These overall results indicate that all of the factors predict use positively, but quite unremarkably (as would be expected if the results of a wide variety of systems were combined). These results suggest and imply that games should not be grouped into a singular system type. Also from a technology acceptance perspective, more meaningful results would be obtained through separately investigating leisure and utilitarian games. These finding reflect more recent discussions around the explanatory power of the technology acceptance model (e.g. Salovaara \& 
RUNNING TITLE: Why do people play games? A meta-analysis

Tamminen 2009) where a central arguments is that TAM does not consider variety in an individual's use purposes and motivations, nor differences in system types (e.g. in this case the difference between hedonic and utilitarian games). Instead, it seems to produce uninformative averages from significantly varying data.

If and when we subscribe to this view, then it is crucial to add further resolution to the analysis. Therefore, we conducted separate meta-SEM analyses for utilitarian games and hedonic games. As can be seen from the results (Figure 6), there are several path coefficients which noticeably vary between the game types. Nevertheless, attitude still predicts playing intention most strongly for both games types and there is no noticeable difference in path coefficient magnitude (H: $0.468 * * *$, U: $\left.0.488^{* * *}\right)$. Enjoyment is clearly more significant for hedonic games as the path coefficient between enjoyment and playing intention (H: $0.292 * * *, \mathrm{U}: 0.052 *)$, and between enjoyment and attitude (H: $\left.0.457^{* * *}, \mathrm{U}: 0.039^{*}\right)$ are both noticeably higher for hedonic games. Conversely for utilitarian games, perceived usefulness has a stronger relationship with playing intention (H: $\left.0.050^{* * *}, \mathrm{U}: 0.268^{* * *}\right)$, and especially with attitude (H: $\left.0.167 * * *, \mathrm{U}: 0.810^{* * *}\right)$. Utilitarian and hedonic games seems to be mirror images of each other concerning their relationships between usefulness, enjoyment, attitude and use intentions. Moreover, perceived ease of use has a stronger connection with both perceived usefulness (H: 0.294***, U: 0.639***) and enjoyment (H: 0.396***, U: 0.506***) for utilitarian rather than hedonic games. Perceived ease of use has a small or insignificant path coefficient with attitude for both game categories $(\mathrm{H}$ : $0.108^{* * *}, \mathrm{U}: 0.023^{\mathrm{ns}}$ ). These findings further cement our view that games clearly divide into hedonic and utilitarian categories. 


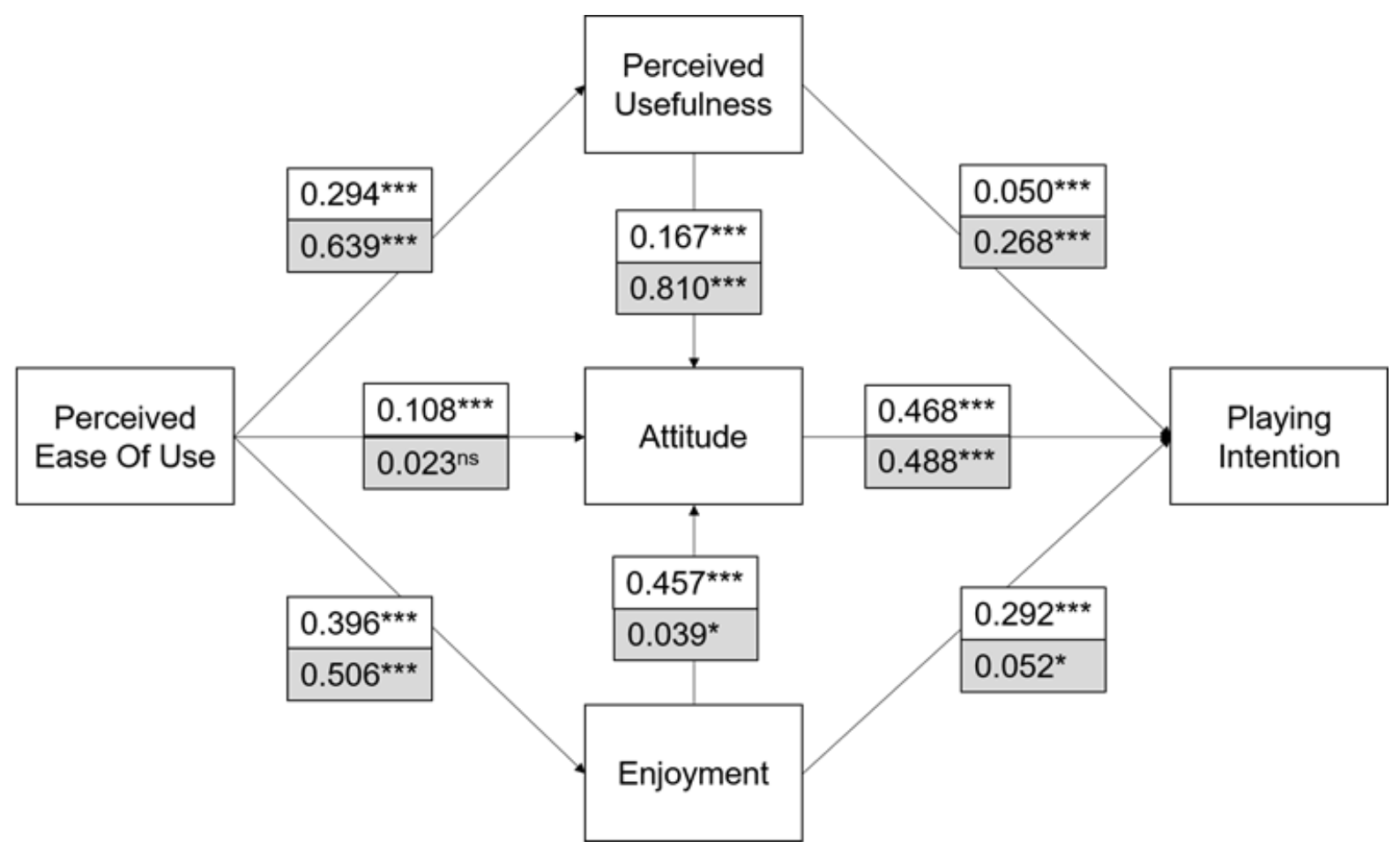

Figure 6: Results for structural equation modeling for hedonic and utilitarian games. ${ }^{* \star} p<0.001$, ${ }^{* *} p<0.01,{ }^{*} p<0.05,{ }^{n s} p>0.05$. Path coefficients individually for hedonic games and utilitarian games.

We notice that the meta-SEM results concerning the strength of the path coefficient between enjoyment and playing intention differs greatly from the correlation-based meta-analysis. Closer examination leads us to believe that this is caused by the high correlation between enjoyment and usefulness, especially for utilitarian games (U: 0.748***; H: 0.492***). This consequently leads usefulness to have a significantly higher explanatory power over enjoyment in the regressionbased meta-SEM model for utilitarian games. Rather than suggesting a possible problem in the data, this high correlation suggests that the relationship between usefulness and enjoyment is theoretically different for games that are being played for instrumental ends. In the correlationbased meta-analysis, the overlapping effect of variables goes unnoticed as only variable pairs are analyzed. 
RUNNING TITLE: Why do people play games? A meta-analysis

Therefore, in order to investigate the theoretical fit, the role of usefulness and enjoyment, and how they may differ between utilitarian and hedonic games, a meta-SEM model fit investigation is needed. Model fit analyses (Table 6) reveal that the extended TAM-model (above - based on Van der Heijden 2004) shows a rather poor model fit from the whole sample (AGFI: 0.417, TLI: 0.468, CFI: 0.894, SRMR: 0.106, RMSEA: 0.340) for exclusively hedonic (AGFI: 0.480, TLI: 0.370, CFI: 0.874, SRMR: 0.117, RMSEA: 0.320) and utilitarian games (AGFI: -0.126, TLI: 0.225, CFI: 0.845, SRMR: 0.159, RMSEA: 0.526). This call into question whether the model structure is in fact appropriate for modelling the acceptance of games, since we suspect that the relationship between usefulness and enjoyment may be more complex than would be the case with traditional information systems. Therefore, based on our theorization about the relationship between usefulness and enjoyment, we explored this further by modelling the relationship between usefulness and enjoyment.

\subsection{2. $\quad$ Modeling use intention of utilitarian games}

Utilitarian games (gamification, serious games etc.) are an intriguing combination of both utilitarian and hedonic systems, where the goals of the systems' use are related to productivity, although the means and the design by which the systems promote productivity are hedonic in nature. Utilitarian games can hence be characterized as “productivity through fun”. If this theorization holds, we should be able to establish a better fitting model version of the TAM whereby enjoyment is mediated by usefulness (Figure 7).

The model fit significantly improved from the original model structure that was used for utilitarian games (AGFI: 0.916, TLI: 0.962, CFI: 0.992, SRMR: 0.022, RMSEA: 0.116). Pertaining to the relationships between variables, the results show significant and strong path 
RUNNING TITLE: Why do people play games? A meta-analysis

coefficients between attitude and playing intention $\left(0.481^{* * *}\right)$ and between perceived usefulness and intention $\left(0.304^{* * *}\right)$. Moreover, perceived usefulness has extremely large effect on attitude $\left(0.810^{* * *}\right)$, whereas the path coefficients from both enjoyment and perceived ease of use on attitude remain insignificant $\left(0.039^{\text {ns }}\right.$ and $0.023^{\text {ns }}$, respectively). However, the relationship between enjoyment and perceived usefulness is strong $\left(0.571^{* * *}\right)$. Finally, perceived ease of use has significant effects on enjoyment and perceived usefulness $\left(0.506^{* * *}\right.$ and $\left.0.350 * * *\right)$.

In order to confirm our theorization about the difference in the roles of enjoyment and usefulness between hedonic and utilitarian games, we also needed to test whether the same model has a conversely poor fit for hedonic games. In viewing the results, we find that the same model does not have good fit for hedonic games (AGFI: 0.727, TLI: 0.697, CFI: 0.939, SRMR: 0.049, RMSEA: 0.222), indicating that a different model structure is needed to explain the acceptance of different types of games along the utilitarian vs hedonic categorization.

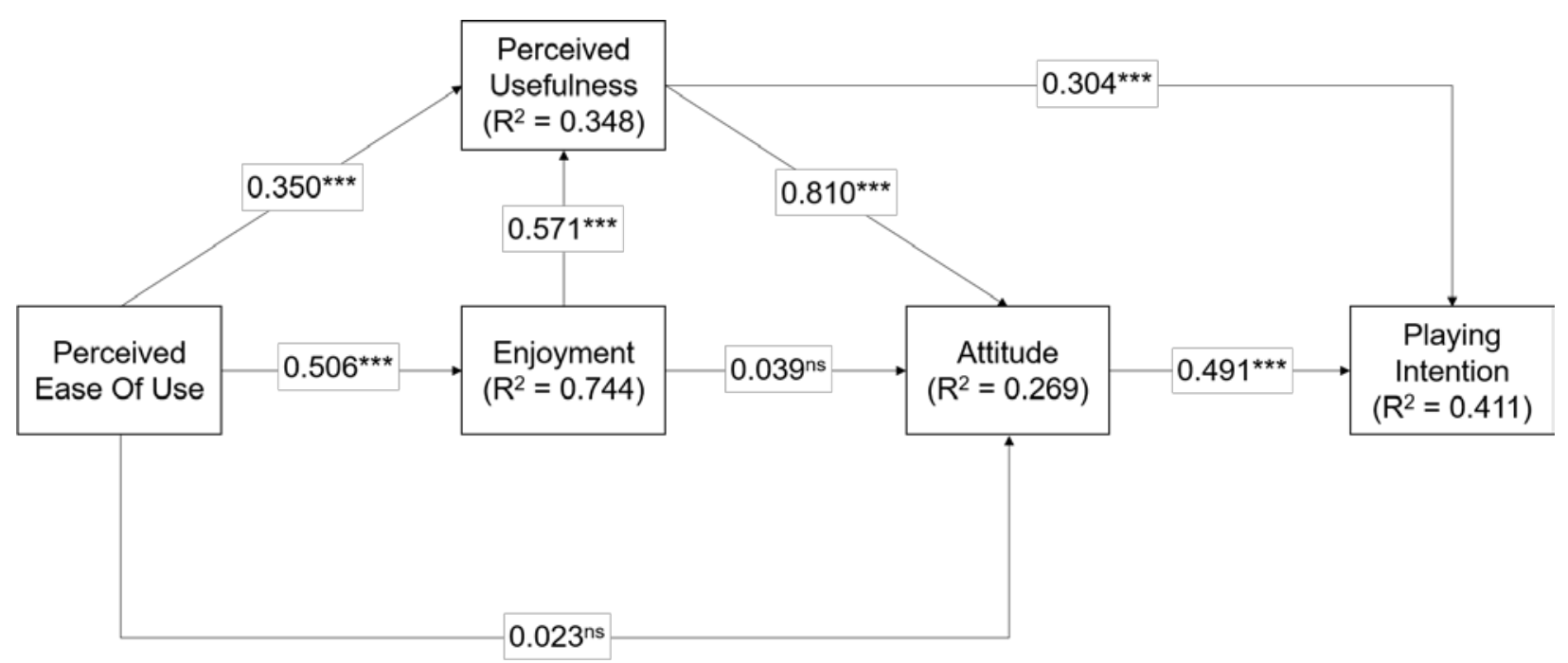

Figure 7: Modeling results for playing intention of utilitarian games. Model fit $=$ AGFI: 0.916, TLI: 0.962, CFI: 0.992, SRMR: 0.022, RMSEA: 0.116. 
RUNNING TITLE: Why do people play games? A meta-analysis

\subsubsection{Modeling use intention of hedonic games}

Having confirmed a fitting model for utilitarian games in the previous sub-section, the question still remains as to what might be a fitting model for hedonic games. In the main meta-SEM analyses, we found that the results between hedonic and utilitarian games seemed mirror images of each other: usefulness was a strong predictor of acceptance of utilitarian games, whilst enjoyment served as a predictor of acceptance for hedonic games. Therefore, there is reason to believe that the relationship and role of enjoyment and usefulness might also be oppositely true. However, hedonic games are not commonly intended for useful purposes, which makes the data correlations of usefulness seem surprisingly strong (PU x INT: 0.392***, PU x ATT: 0.423***). Given that the correlation analysis also revealed a strong association between usefulness and enjoyment $\left(0.492^{* * *}\right)$, we should examine the causal relationship between these variables. These results lead us to believe that perhaps usefulness relates to a game's ability to fulfill hedonic needs in hedonic games, and thus a higher sense of usefulness increases the actual enjoyment of playing the games. Therefore, we proceeded to analyze the model fit of a model where the places of usefulness and enjoyment have been reversed.

Similar to utilitarian games, the results for hedonic games (Figure 8) show a strong relationship between attitude and playing intention $(0.479 * * *)$. Moreover, enjoyment has a significant path coefficient to playing intention $\left(0.311^{* * *}\right)$ and also to attitude $\left(0.457^{* * *}\right)$. In addition, perceived usefulness and perceived ease of use have significant but subtle relationships with attitude $(0.167 * * *$ and $0.108 * * *$, respectively). Interestingly, enjoyment and perceived usefulness are strongly associated $\left(0.411^{* * *}\right)$. Lastly, ease of use has similar and significant effects on both perceived usefulness and enjoyment $\left(0.294^{* * *}\right.$ and $\left.0.275^{* * *}\right)$. 
RUNNING TITLE: Why do people play games? A meta-analysis

In order to confirm our theorization about the difference between use motivation differences between hedonic and utilitarian games, we also needed to test whether conversely the same model now has a poor fit for utilitarian games. The indices indicate a significantly more appropriate model for hedonic (AGFI: 0.980, TLI: 0.980, CFI: 0.996, SRMR: 0.014, RMSEA: 0.056) rather than utilitarian (AGFI: 0.824, TLI: 0.916, CFI: 0.983, SRMR: 0.032, RMSEA: 0.173) types of games, where most of the indices do not reach acceptance thresholds. For hedonic games, all of the indices are acceptable and therefore these model fits further support our theorization.

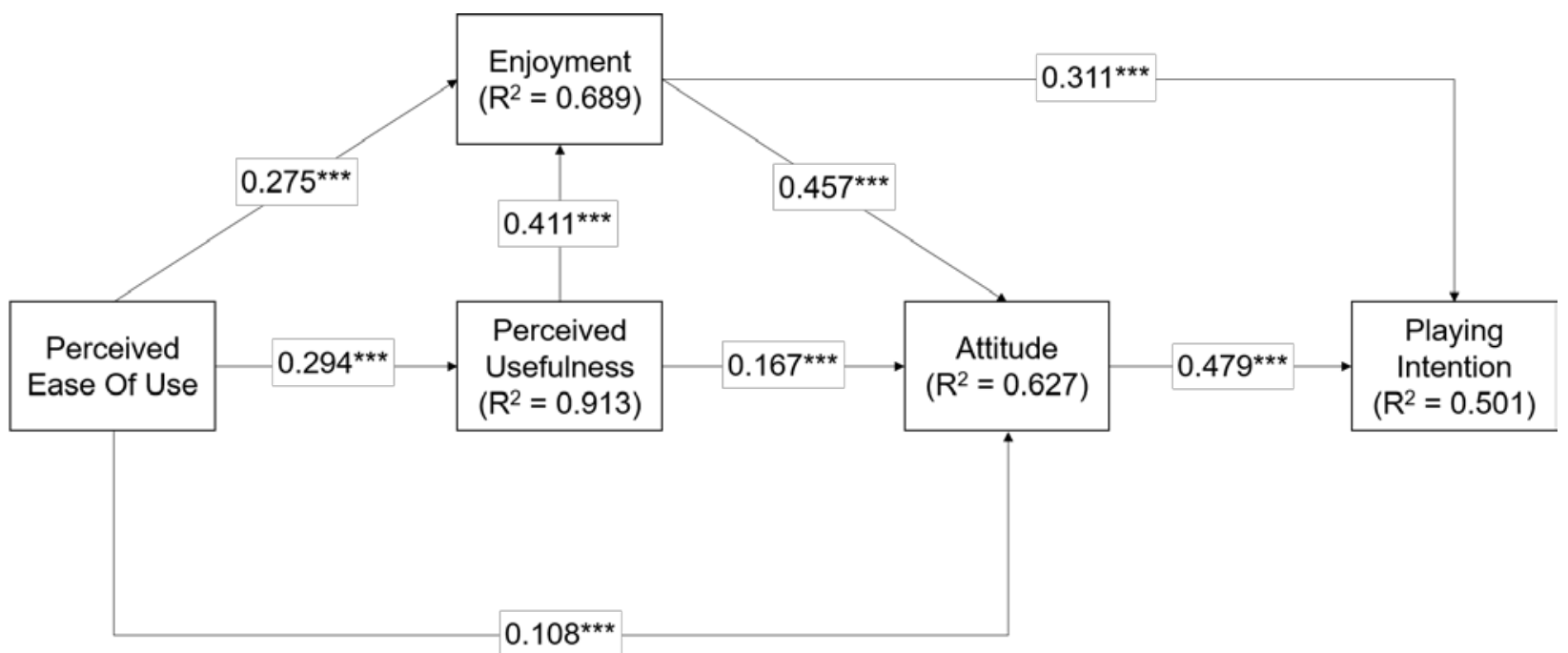

Figure 8: Modeling results for playing intention of hedonic games. Model fit $=$ AGFI: 0.980 , TLI: 0.980, CFI: 0.996, SRMR: 0.014, RMSEA: 0.056. 
RUNNING TITLE: Why do people play games? A meta-analysis

Table 6: Model fit indices.

\begin{tabular}{|c|c|c|c|c|c|c|}
\hline & $\chi^{2}(d f)$ & AGFI & TLI & $\mathrm{CFI}$ & SRMR & RMSEA \\
\hline \multicolumn{7}{|c|}{ Model 1 (Figure 5 \& 6) } \\
\hline All games & $\chi^{2}(2)=1340.6 ; p<0.001$ & 0.417 & 0.468 & 0.894 & 0.106 & 0.340 \\
\hline Hedonic & $\chi^{2}(2)=825.1 ; p<0.001$ & 0.480 & 0.370 & 0.874 & 0.117 & 0.320 \\
\hline Utilitarian & $\chi^{2}(2)=617.7 ; p<0.001$ & -0.126 & 0.225 & 0.845 & 0.159 & 0.526 \\
\hline \multicolumn{7}{|c|}{ Model 2 (Figure 7) } \\
\hline Hedonic & $\chi^{2}(2)=398.1 ; p<0.001$ & 0.727 & 0.697 & 0.939 & 0.049 & 0.222 \\
\hline Utilitarian & $\chi^{2}(2)=32.2 ; p<0.001$ & 0.916 & 0.962 & 0.992 & 0.022 & 0.116 \\
\hline \multicolumn{7}{|c|}{ Model 3 (Figure 8) } \\
\hline Hedonic & $\chi^{2}(2)=27.6 ; p<0.001$ & 0.980 & 0.980 & 0.996 & 0.014 & 0.056 \\
\hline Utilitarian & $\chi^{2}(2)=69.0 ; p<0.001$ & 0.824 & 0.916 & 0.983 & 0.032 & 0.173 \\
\hline Acceptable & & $>0.90$ & $>0.90$ & $>0.90$ & $<0.08$ & $<0.07$ \\
\hline \multirow[t]{2}{*}{ Excellent } & $p>0.05$ & $>0.95$ & $>0.95$ & $>0.95$ & $<0.05$ & $<0.03$ \\
\hline & (Hooper et al. 2008) & & \multicolumn{4}{|c|}{ (Hair et al. 2010; Hu \& Bentler 1999) } \\
\hline
\end{tabular}

\section{DISCUSSION}

The present study contributed to and advanced the theoretical and empirical understanding of the nature of games, and also their role in the vast space of information systems and the related academic domain. Moreover, through this examination of games, the paper has also contributed to improving our understanding of information systems that can't clearly be placed in the traditional categories of either utilitarian or hedonic information systems. The study offers important insights about the differing and similar motivations which relate to the dualpurposefulness of these types of ISs, and also provides methodological guidelines (especially related to meta-analysis) that can be further employed in mapping user motivations across IS types across the whole body of literature which has been conducted in the IS field. As far as we know, the present study is one of the first of its kind in the area of information systems that employs rigorous mathematical meta-analytical methods, including meta-SEM. 
RUNNING TITLE: Why do people play games? A meta-analysis

More specifically, this study has synthesized previous research literature meta-analytically and provided estimates for the correlations between the most common variables featured in studies that investigate why people use games. Since we utilized zero-order correlations between variables as our data, we were not restricted by the theoretical assumptions or model structures which occurred in the reviewed body of literature. In addition, we conducted a meta-SEM analysis employing an extended technology acceptance model (Van der Heijden 2004) to model use intention, and investigated the differences between hedonic and utilitarian types of games. The results showed several factors that have significant correlation with playing intention. However, above all else, attitude remained the strongest determinant of game use, independent of the game type. The results also reveal significant differences between the game categories. Predictably, utilitarian game use is ultimately determined by usefulness, whereas hedonic games are mainly played for enjoyment. However, the analysis also showed a strong association between enjoyment and usefulness, revealing that the respective lesser determinants had a significant but indirect role in explaining use intention. Therefore, it can be posited that games are multi-purpose ISs which nevertheless rely on hedonic factors, even in the pursuit of instrumental outcomes.

Traditionally, information systems have been divided into hedonic and utilitarian categories in accordance to their primary use purpose. Literature suggests that while utilitarian information systems are primarily used for usefulness (Davis 1989), the use of hedonic systems is mainly driven by enjoyment (Van der Heijden 2004). More recently, however, IS scholars have observed that some systems (known as dual-purposed IS) can be employed for both utilitarian and leisure purposes (Gerow et al. 2013; Lowry et al. 2013; Soliman \& Tuunainen 2015; Wu \& Lu 2013). A prominent example of such systems are social networking services which are 
RUNNING TITLE: Why do people play games? A meta-analysis

commonly used for either work or leisure purposes. Although games are often regarded as the most extreme form of hedonic information systems, our results show that games are also dualpurpose ISs in the sense that their use is driven by both hedonic and utilitarian reasons. However, our results also show that the dual-purpose can be different. For example, where social networking services may be used for work during the day and for leisure during leisure hours, games require their enjoyment and usefulness to manifest simultaneously; however, in utilitarian games, enjoyment is a pre-requirement for their instrumentality. Therefore, the present metaanalysis has been able to tease out the nature of a new form of dual/multi-purpose where the use is dual-purposed, but rather than the purposes taking turns, they may exist at the same time and in a causal relationship.

In particular, we have managed to show that while some games are primarily played for entertainment, the use of others is mainly motivated by usefulness. Having fun while playing utilitarian games improves the sense of usefulness, whereas hedonic games only need to be useful in the sense that they can fulfill the player's hedonic needs effectively. Therefore, instead of classifying games as purely hedonic information systems, our results show that it is more appropriate to identify games as dual-purposed information systems. Moreover, unlike the findings of previous research (Wu \& Lu 2013), our results imply that enjoyment does not necessarily play the most important role in determining the use of dual-purposed information systems. Instead, we suggest that main motivator for use varies with the temporary use purpose: if games are used for education or other utilitarian outcome purposes, then their primary use motivator shifts from enjoyment to usefulness. 
RUNNING TITLE: Why do people play games? A meta-analysis

In the grander scheme of theories about why people use different systems and services, while the utilitarian-hedonic continuum has been the most dominant one, more recent work has also heavily incorporated social aspects among main determinants of IS use in addition to utilitarian and hedonic factors (See. e.g. Hamari \& Koivisto 2015; Li \& Mao 2015; Mäntymäki \& Riemer 2014; Ngai et al. 2015). Relatedly, research on player typologies and player orientations have also identified social gaming orientation as one the main approaches that people have towards playing (Hamari \& Tuunanen 2014; Kallio et al. 2011; Yee 2006a). As seems clearly apparent, gaming and playing are inherently social activities (and even more so after the advent of online games), and therefore, investigating social gratifications and motivations along with hedonic and utilitarian ones seems to be increasingly essential. Future studies could, for example, more comprehensively investigate sense of community that cooperative games might give rise to, recognition that players derive from in-game achievements and for example trust that games may help build between players working together.

According to popular behavioral theories such as the technology acceptance model (Davis 1989), theory of reasoned action (Ajzen \& Fishbein 1980), and the theory of planned behavior (Ajzen 1991), attitude is commonly assumed to be the strongest determinant of behavioral intentions and actual behavior. Our analysis also confirms these assumptions, and across game types, attitude was the strongest determinant for game use. However, attitude is a rather abstract variable on its own, and therefore often modeled in middle of multilevel model structures. In fact, our results revealed that perceived usefulness and enjoyment had significantly stronger effects on attitude than directly on playing intention, indicating that attitude is an important mediator of other main motivations for game use. 
RUNNING TITLE: Why do people play games? A meta-analysis

In the technology acceptance model (Davis et al. 1989), perceived ease of use indirectly explains information system use by having effects on usefulness and attitude. In addition to these relationships, we also modeled the causal path from ease of use to enjoyment. According to the results, a higher usability of games seems to enable enjoyable gaming experiences as well as enhance the sense of usefulness of playing them. It is highly plausible that difficulties and frustration in the user interface may detract from game enjoyment, and also hinder utilitarian outcomes. However, the relationship between ease of use and attitude was surprisingly weak. In particular, as the zero-order correlation between the variables was noticeably stronger than the path coefficient in our structural model, the results suggest that enjoyment and usefulness dominate the effects on attitude over the perceived ease of use. In the end, while usability is important for enjoyment and usefulness, it does not seem to directly modify our attitude towards playing games.

Prior to conducting our meta-SEM analyses, we examined several variables and their direct relationships with playing intention. This allowed us to investigate a broader set of variables and their effects, despite that not all of the variables could be included in the SEM-analyses. In addition to enjoyment, the literature has suggested two other hedonic variables to explain the use of games; flow and perceived playfulness. Flow is the extent of deep concentration, the amount of immersion and the optimal hedonic experience (Csikszentmihalyi 1990) in the use of games, whereas perceived playfulness is related to interestingness and curiosity (Moon \& Kim 2001). While differences exist between their details, they similarly represent hedonic aspects of the game. Thus, in our study we expected to find similar results as we did with enjoyment. While the results expectedly showed significant relationships between both variables and playing intention, their correlations were noticeably weaker than for enjoyment. However, flow and playfulness are 
RUNNING TITLE: Why do people play games? A meta-analysis

relatively detailed and specific experiences in comparison to enjoyment, which represents a hedonic experience of playing games in general. As there were a wide variety of game types in this analysis, the significance of these variables might vary from one game type to another. For example, although playing mobile games can be as much fun as playing any other games, they are typically played for shorter periods and do not offer as immersive experiences and interesting content as computer games might. Similarly, many games are considerably goal-driven and taskoriented, and this may give relatively less space for playful behavior and experiences which are driven by curiosity, exploration and free play (Webster \& Martocchio 1992). While our sample unfortunately did not allow us to examine this aspect comprehensively, future efforts could further examine why the results for flow and playfulness were slightly weaker than those for enjoyment.

Three studies modeled how satisfaction with games affects use intention, and all managed to detect an effect in their structural models. Thus, it therefore inevitable that our meta-analysis would also conclude that a connection existed between these variables. However, while the effect was significant and quite strong, the estimate had huge confidence intervals. Although all of the studies showed an effect, the wide intervals were due to highly varying correlations between the studies. By looking at the details, the results revealed that there was a clear difference in the estimates between a single education game study (high correlation) and two studies which examined social network games (low correlations). Moreover, a surprisingly weak relationship between satisfaction and use behavior has also been discussed in online games (Tseng \& Wang 2012), where satisfaction poorly explained behavior. Although these findings imply differences between hedonic and utilitarian games, the low number of studies did not allow comprehensive and accurate conclusions to be drawn on the variability of this effect. 
RUNNING TITLE: Why do people play games? A meta-analysis

Nevertheless, the effects of satisfaction on the use of games requires more investigation, especially due to the surprisingly weak correlations seen in the two social network game studies.

Subjective norms is the perception of whether other people approve the behavior or not, and is one of the main determinants for behavioral intention in the theories of reasoned action (Ajzen \& Fishbein 1980) and planned behavior (Ajzen 1991). According to these theories, the playing intention of games should depend on subjective norms. The results indeed revealed a significant relationship between subjective norms and playing intention, however, it was only mediocre in its strength. This finding is rather expected, and while subjective norms should not be the most important reason for using games, social pressure should still have an effect on the behavior. However, while subjective norms were the most frequently studied social aspect in the analyzed literature, they insufficiently describe the actual social reasons for playing. Since most contemporary games include social activities such as multiplayer game modes, chatting, trading and/or tools for sharing the gaming experience, social factors are arguably an important consideration in the use of games. Indeed, studies have discovered that some people play primarily because they can interact with other players (Bartle 1996). Therefore, it would be wise to study the relationship between playing intention and the social reasons for playing more extensively.

Traditionally, young men are the stereotypical users of games. However, the increased popularity of games has significantly increased the number of different players, and currently, not only is the concept of this stereotypical player becoming outdated, but the division of genders in game users has become rather even (ESA 2014). This review also supports the view that the legacy mindset of considering games as merely the pastimes of pre-adolescent males is unfounded. The 
RUNNING TITLE: Why do people play games? A meta-analysis

results of this meta-analysis could not detect any significant correlation between gender and playing intention, and is thus breaking the stereotype.

It can be noted that this study attempted to investigate the why people play games metaanalytically and by emphasizing rigor of investigation over novelty or relevance by including variables and perspectives that had been cover extensively enough in the extant literature. In contrast, especially in the context of qualitative game research literature, games are commonly viewed from a wider set of perspectives. This study focused only of variables and factors that had been investigated in enough quantitative literature to afford a meta-analytical investigation. However, it can be said that while game research literature has been interested in games from multiple perspectives, it has only been the information systems literature that has studies game use in a way that afforded it being used as data for the meta-analysis. This notion poses a few implications for the future research both the IS literature as well as game research outside the IS realm. Firstly, it is clear that information systems literature, both for its detriment and benefit, the area has been dominated by rigid theoretical framework which dictate the bulk of research models used in empirical investigation. However, this setting has at the same time being limiting to how variedly games have been investigated. An indication of this was the fact that in this review only studies that had employed factors familiar from the technology acceptance literature could be included in the meta-SEM analyses as only those had been investigated enough times. Therefore, it is clear that quantitative literature that investigates the relationship between playing activities and motivations as well as gratification from it is still scarce. There is a plethora of singular studies that have investigated any given factor and there is not yet enough cumulated literature to compare findings across these studies that deviate from the technology acceptance theory's core. In order for us to understand games and why do people use them more holistically, 
RUNNING TITLE: Why do people play games? A meta-analysis

but at the same time rigorously, researchers seeking to make their dent in this vein of literature should boldly venture towards more courageous research initiatives and towards including a more varied set of independent variables. However, these efforts should at the same time seek to retain the comparability of their research to e.g. the body of literature meta-analyzed here.

\section{1. $\quad \underline{\text { Limitations }}$}

As far as we know, our study is the first of its kind to conduct comparative (meta-)analyses on the use and acceptance of hedonic and utilitarian games. This comparison has been direly needed not only for the sake of game research, but also to contribute to our understanding of the process of adoption between types of a same class of technology. However, future studies should look even deeper into more nuanced categories and types. This would have been impossible in this study, since the amount of available literature is still too small to provide enough resolution to investigate more nuanced categories, and therefore, we were restricted to the level of the hedonic-utilitarian continuum. Although we can categorize games into hedonic and utilitarian types with reasonable accuracy based on their main leisure or instrumental purpose, the specific game types remain rather abstract. In particular, the hedonic category consisted of studies reporting online, MMO, mobile and social network games. While these games share a leisure oriented nature, they can still be relatively different and even overlap each other. In order to develop a more detailed and fine grained division of game types, we would have needed more specific information about the games specifically examined in the literature. However, these game types were named as they were reported, thus prohibiting us from conducting a more detailed game type analysis. In fact, it seemed as if most of the studies we analyzed could not specify the game types themselves, as the questionnaires they employed were often targeted to 
RUNNING TITLE: Why do people play games? A meta-analysis

one of the listed game types rather than for specific games. Especially, as this review has revealed that different type of games are likely to have different use motivations, then future efforts should be more specific regarding the games they examine. Such specificity allows scholars to use more specific and interesting variables, rather than generic variables such as attitude, usefulness or enjoyment. Currently it seems that not enough literature has appeared which makes comparisons between more specific groupings. However, the split between utilitarian and hedonic games is rather defendable as the end-utility of these types clearly differ (despite that utilitarian games can be enjoyable etc.).We acknowledge some challenges in the combination of variables across studies. Undoubtedly not all of the studies measured similarly named variables identically, and so conceptually, merging variables across a variety of studies could be seen as rather questionable. However, in practice it is difficult to find even two independent studies which employ identical measures (Ellis 2010). That said, combining similar concepts with slightly varying details is not necessarily a study weakness, and a slight variation in variable constructs covers the concept more comprehensively, and can thus provide more accurate overall estimates when enough studies are included in the meta-analysis.

\section{REFERENCES}

Ajzen, I. (1991) The theory of planned behavior, Organizational behavior and human decision processes 50(2): 179-211.

Ajzen, I. and Fishbein, M. (1980) Understanding Attitudes and Predicting Social Behavior, Englewood Cliffs, NJ: Prentice-Hall. 
RUNNING TITLE: Why do people play games? A meta-analysis

Alha, K., Koskinen, E., Paavilainen, J., Hamari, J., and Kinnunen, J. (2014) Free-to-Play games:

Professionals’ perspectives. In Proceedings of Nordic Digra 2014, Gotland, Sweden, May 29, 2014.

Alha, K., Koskinen, E., Paavilainen, J., and Hamari, J. (2016) Critical Acclaim and Commercial Success in Mobile Free-to-Play Games. In Proceedings of DiGRA FDG Conference, Dundee, Scotland, 1-6 August, 2016.

Bartle, R. (1996) Hearts, clubs, diamonds, spades: Players who suit MUDs, [Online] Available at: http://www.mud.co.uk/richard/hcds.htm

Bhattacherjee, A. (2001) Understanding information systems continuance: An expectationconfirmation model, MIS Quarterly 25(3): 351-370.

Boell, S. K. and Cecez-Kecmanovic, D. (2014) On being 'systematic' in literature reviews in IS, Journal of Information Technology 30(2): 161-173.

Borenstein, M., Hedges, L. V. Higgins, J. P. T. and Rothstein, H. R. (2009) Introduction to metaanalysis, Chichester: Wiley.

Bourgonjon, J., Valcke, M., Soetaert, R. and Schellens, T. (2010) Students' perception about the use of video games in the classroom, Computers \& Education 54(4): 1145-1156.

Chang, C.-C. (2013) Examining users' intention to continue using social network games: A flow experience perspective, Telematics and Informatics 30(4): 311-321. 
RUNNING TITLE: Why do people play games? A meta-analysis

Chang, I.-C., Liu, C.-C. and Chen, K. (2014) The effects of hedonic/utilitarian expectations and social influence on continuance intention to play online games, Internet Research 24(1): 21-45.

Cheng, Y.-M., Lou, S.-J., Kuo, S.-H. and Shih, R.-C. (2013) Investigating elementary school students' technology acceptance by applying digital game-based learning to environmental education, Australasian Journal of Educational Technology 29(1): 96-110.

Chen, L. S.-L. and Kuan, C. J. (2012) Customer acceptance of playing online game on mobile phones, International Journal of Mobile Communications 10(6): 598-616.

Cheung, M. W.-L. (2015) Meta-analysis: A structural equation modeling approach, s.l.:John Wiley \& Sons.

Cochran, W. G. (1954) The combination of estimates from different experiments, Biometrics 10(1): 101-129.

Cohen, J. (1988) Statistical Power Analysis for the Behavioral Sciences, 2nd ed. Hillsdale: Lawrence Erlbaum.

Csikszentmihalyi, M. (1990) Flow: The psychology of optimal experience, New York, NY: Harper and Row.

Davis, F. D. (1989) Perceived usefulness, perceived ease of use, and user acceptance of information technology, MIS Quarterly 13(3): 319-340. 
RUNNING TITLE: Why do people play games? A meta-analysis

Davis, F. D. Bagozzi, R. P. and Warshaw, P. R. (1989) User acceptance of computer technology: a comparison of two theoretical models, Management Science 35(8): 982-1003.

Davis, F. D. Warshaw, P. R. and Bagozzi, R. P. (1992) Extrinsic and intrinsic motivation to use computers in the workplace, Journal of Applied Social Psychology 22(14): 1111-1132.

Ellis, P. D. (2010) The essential guide to effect sizes: Statistical power, meta-analysis, and the interpretation of research results, Cambridge: Cambridge University Press.

Elsevier B.V, (2014) Online tools - Scopus, [Online]

Available at: http://www.elsevier.com/online-tools/scopus

[Accessed 2410 2014].

ESA, (2014) Essential facts about the computer and video game industry: 2014 sales, demographic, and usage data, [Online]

Available at: http://www.theesa.com/facts/pdfs/ESA_EF_2014.pdf

[Accessed 23 November 2014].

Field, A. P. (2005) Is the meta-analysis of correlation coefficients accurate when population correlations vary?, Psychological Methods 10(4): 444-467.

Gerow, J. E. Ayyagarai, R., Thatcher, J. B. and Roth, P. L. (2013) Can we have fun @ work? The role of intrinsic motivation for utilitarian systems, European Journal of Information Systems 22: $360-380$. 
RUNNING TITLE: Why do people play games? A meta-analysis

Glass, G. V. (1981) Meta-Analysis in Social Research, Beverly Hills, CA: Sage Publications.

Greenberg, B. S., Sherry, J., Lachlan, K., Lucas, K. and Holmstrom, A. (2010) Orientations to video games among gender and age groups, Simulation and Gaming 41(2): 238-259.

Griffiths, M. D., Davies, M. N. O. and Chappell, D. (2003) Breaking the stereotype: The case of online gaming, CyberPsychology and Behavior 6(1): 81-91.

Griffiths, M. D., Davies, M. N. O. and Chappell, D. (2004) Demographic factors and playing variables in online computer gaming, Cyberpsychology and Behavior 7(4): 479-487.

Hair, J. F. Black, W. C. Babin, B. J. and Anderson, R. E. (2010) Multivariate data analysis, Englewood Cliffs, NJ: Prentice Hall.

Hall, S. M. and Brannick, M. T. (2002) Comparison of two random-effects methods of metaanalysis, Journal of Applied Psychology 87(2): 377-389.

Hamari, J. (2015) Why do people buy virtual goods? Attitude toward virtual good purchases versus game enjoyment, International Journal of Information Management 35(3): 299-308.

Hamari, J., Alha, K., Järvelä, S., Kivikangas, J. M., Koivisto, J., and Paavilainen, J. (2017a) Why do players buy in-game content? An empirical study on concrete purchase motivations. Computers in Human Behavior, 68: 538-546. 
RUNNING TITLE: Why do people play games? A meta-analysis

Hamari, J., Hanner, N., \& Koivisto, J. (2017b) Service quality explains why people use freemium services but not if they go premium: An empirical study in free-to-play games, International Journal of Information Management, 37(1): 1449-1459.

Hamari, J., Huotari, K. and Tolvainen, J. (2015) Gamification and Economics, in S. P. Walz \& S. Deterding, (ed.) Gamification and Economics, Cambridge, MA: MIT Press, pp. 139-161.

Hamari, J. and Järvinen, A. (2011) Building Customer Relationship through Game Mechanics in Social Games, in M. Cruz-Cunha, V. Carvalho \& P. Tavares, (ed.) Building Customer Relationship through Game Mechanics in Social Games, Hershey, PA: IGI Global, pp. 348-365.

Hamari, J. and Koivisto, J. (2015) Why do people use gamification services?, International Journal of Information Management 35(4): 419-431.

Hamari, J. and Lehdonvirta, V. (2010) Game Design as Marketing: How Game Mechanics Create Demand for Virtual Goods, International Journal of Business Science \& Applied Management 5(1): 14-29.

Hamari, J., Shernoff, D. J., Rowe, E., Coller. B., Asbell-Clarke, J., and Edwards, T. (2016) Challenging games help students learn: An empirical study on engagement, flow and immersion in game-based learning. Computers in Human Behavior, 54: 170-179.

Hamari, J., and Sjöblom, M. (2017) What is eSports and why do people watch it? Internet research, 27(2). 
RUNNING TITLE: Why do people play games? A meta-analysis

Hamari, J. and Tuunanen, J. (2014) Player types: A meta-synthesis, Transactions of the Digital Games Research Association 1(2): 29-53.

Hartmann, T., Jung, Y. and Vorderer, P. (2012) What determines video game use? The impact of users' habits, addictive tendencies, and intentions to play, Journal of Media Psychology 24(1): 19-30.

Hedges, L. V. (1981) Distribution theory for Glass's estimator of effect size and related estimators, Journal of Educational Statistics 6(2): 106-128.

Hedges, L. V. (1992) Meta-analysis, Journal of Educational Statistics 17(4): 279-296.

Hedges, L. V. and Olkin, I. (1985) Statistical Methods for Meta-Analysis, London: Academic Press.

Hedges, L. V. and Vevea, J. L. (1998) Fixed- and random-effects models in meta-analysis, Psychological Methods 3(4): 486-504.

Hernon, P. and Whitman, J. (2001) Delivering satisfaction and service quality: A customer-based approach for libraries, Chicago: Americal library association.

Higgins, J. P. T. and Thompson, S. G. (2002) Quantifying heterogeneity in a meta-analysis, Statistics in medicine 21(11): 1539-1558. 
RUNNING TITLE: Why do people play games? A meta-analysis

Hong, J.-C., Hwang, M.-Y., Wang, C.-K., Hsu, T.-F., Chen, Y.-J. and Chan, C.-H. (2011) Effect of Self-worth and Parenting Style on the Planned Behavior in an Online Moral Game, Turkish Online Journal of Educational Technology 10(2): 82-90.

Hooper, D., Coughlan, J. and Mullen, M. R. (2008) Structural equation modelling: Guidelines for determining model fit, The Electronic Journal of Business Research Methods 6(1): 53-60.

Hsiao, C.-C. and Chiou, J.-S. (2012) The effects of a player's network centrality on resource accessibility, game enjoyment, and continuance intention: A study on online gaming communities, Electronic Commerce Research and Applications 11(1): 75-84.

Hsiao, C.-C. and Chiou, J.-S. (2012) The impact of online community position on online game continuance intention: Do game knowledge and community size matter?, Information \& Management 49(6): 292-300.

Hsu, C.-L. and Lu, H.-P. (2004) Why do people play on-line games? An extended TAM with social influences and flow experience, Information \& Management 41(7): 853-868.

Huang, L.-Y. and Hsieh, Y.-J. (2011) Predicting online game loyalty based on need gratification and experiential motives, Internet Research 21(5): 581-598.

Hu, L. T. and Bentler, P. M. (1999) Cutoff Criteria for Fit Indexes in Covariance Structure Analysis: Conventional Criteria Versus New Alternatives, Structural Equation Modeling 6(1): 155. 
RUNNING TITLE: Why do people play games? A meta-analysis

Hunter, J. E. and Schmidt, F. L. (2000) Fixed effects vs. random effects meta-analysis models: Implications for cumulative research knowledge, International Journal of Selection and Assessment 8(4): 275-292.

Hunter, J. E. and Schmidt, F. L. (2004) Methods of Meta-Analysis: Correcting Error and Bias in Research Findings, 2nd ed. Newbury Park, CA: Sage Publications.

Huotari, K. and Hamari, J. (2016) A definition for gamification: anchoring gamification in the service marketing literature, Electronic Markets 1-11.

Hwang, M.-Y., Hong, J.-C., Cheng, H.-Y., Peng, Y.-C. and Wu, N.-C. (2013) Gender differences in cognitive load and competition anxiety affect 6th grade students' attitude toward playing and intention to play at a sequential or synchronous game, Computers \& Education 60(1): 254-263.

Ijsselsteijn, W., Nap, H. H., de Kort, Y. and Poels, K. (2007) Digital game design for elderly users, In Proceedings of the 2007 conference on Future Play, Toronto, Canada, November 15-17. ACM. 17-22.

Jansz, J., Avis, C. and Vosmeer, M. (2010) Playing The Sims2: An exploration of gender differences in players’ motivations and patterns of play, New Media Society 12(2): 235-251.

Johnson, B. T. Mullen, B. and Salas, E. (1995) Comparison of three major meta-analytic approaches, Journal of Applied Psychology 80(1): 94-106. 
RUNNING TITLE: Why do people play games? A meta-analysis

Jung, H. S., Kim, K. H. and Lee, C. H. (2014) Influences of perceived product innovation upon usage behavior for MMORPG: Product capability, technology capability, and user centered design, Journal of Business Research 67(10): 2171-2178.

Kallio, K. P., Mäyrä, F. and Kaipainen, K. (2011) At Least Nine Ways to Play: Approaching Gamer Mentalities, Games and Culture 6(4): 327-353.

Kari, T. and Makkonen, M. (2014) Explaining the usage intentions of exergames, In 35th International Conference on Information Systems, Auckland 2014.

Kim, T., Kim, M. C., Moon, G. and Chang, K. (2014) Technology-Based Self-Service and Its Impact on Customer Productivity, Services Marketing Quarterly 35(3): 255-269.

Koivisto, J. and Hamari, J. (2014) Demographic Differences in Perceived Benefits from Gamification, Computers in Human Behavior 35: 179-188.

Koo, D.-M. (2009) The moderating role of locus of control on the links between experiential motives and intention to play online games, Computers in Human Behavior 25(2): 466-474.

Kuo, S.-H., Lou, S.-J., Hsin, T.-H. and Dzan, W.-Y. (2011) The application of digital gamebased learning to idioms education acceptance, In proceedings of the 6th International Conference on E-learning and Games, Edutainment 2011, Taipei, Taiwan, September 2011.

Landis, R. S. (2013) Succesfully combining meta-analysis and structural equation modeling: Recommendations and strategies, Journal of Business and Psychology 28(3): 251-261. 
RUNNING TITLE: Why do people play games? A meta-analysis

Laumer, S., Eckhardt, A. and Weitzel, T. (2012) Online Gaming to Find a New Job - Examining Job Seekers' Intention to Use Serious Games as a Self-Assessment Tool, German Journal of Research in Human Resource Management 26(3): 218-240.

Lee, M.-C. (2009) Understanding the behavioural intention to play online games: an extension of the theory of planned behaviour, Online Information Review 33(5): 849-872.

Lehdonvirta, V. (2009) Virtual item sales as a revenue model: Identifying attributes that drive purchase decisions, Electronic Commerce Research 9(1-2): 97-113.

Li, H., Liu, Y., Xu, X., Heikkilä, J. and van der Heijden, H. (2015) Modeling hedonic IS continuance through the uses and gratifications theory: An empirical study in online games, Computers in Human Behavior 48: 261-272.

Liu, Y. L. and Li, H. (2011) Exploring the impact of use context on mobile hedonic services adoption: An empirical study on mobile gaming in China, Computers in Human Behavior 27(2): 890-898.

Long, J. (2001) An Introduction to and Generalization of the "Fail-Safe N", Paper presented at the Annual Meeting of the Southwest Educational Research Association (New Orleans, LA, February 1-3, 2001).

Lowry, P. B. Gasking, J. E. Twyman, N. W. Hammer, B. and Roberts, T. L. (2013) Taking "fun and games" seriously: Proposing the hedonic-motivation system adoption model (HMSAM), Journal of the Association for Information Systems 14(11): 617-671. 
RUNNING TITLE: Why do people play games? A meta-analysis

Lu, H.-P. and Wang, S.-M. (2008) The role of Internet addiction in online game loyalty: An exploratory study, Internet Research 18(5): 499-519.

McGonigal, J. (2011) Reality is broken: Why games make us better and how they can change the world, London: Jonathan Cape.

Moon, J. and Kim, Y. (2001) Extending the TAM for a world-wide-web context, Information \& Management 38(4): 217-230.

Mäntymäki, M., \& Riemer, K. (2014) Digital natives in social virtual worlds: A multi-method study of gratifications and social influences in Habbo Hotel, International Journal of Information Management, 34(2): 210-220.

Mäntymäki, M., \& Salo, J. (2011). Teenagers in social virtual worlds: Continuous use and purchasing behavior in Habbo Hotel. Computers in Human Behavior, 27(6), 2088-2097.

Mäntymäki, M., \& Salo, J. (2013). Purchasing behavior in social virtual worlds: An examination of Habbo Hotel. International Journal of Information Management, 33(2): 282-290.

Mäntymäki, M., \& Salo, J. (2015) Why do teens spend real money in virtual worlds? A consumption values and developmental psychology perspective on virtual consumption, International Journal of Information Management, 35(1):124-134.

Mäyrä, F. and Ermi, L. (2014) Pelaajabarometri 2013: Mobiilipelaamisen Nousu, TRIM Research Reports: 11, University of Tampere. 
RUNNING TITLE: Why do people play games? A meta-analysis

Naeini, F. H. and BalaKrishnam, (2012) Usage pattern, perceived usefulness and ease of use of computer games among malaysian elementary school students, Research Journal of Applied Sciences, Engineering and Technology 23(4): 5285-5297.

Ngai, E. W., Tao, S. S., and Moon, K. K. (2015) Social media research: Theories, constructs, and conceptual frameworks. International Journal of Information Management, 35(1): 33-44.

Oates, B. J. (2015) On systematic reviews for evidence-based practice, Journal of Information Technology 30(2): 177-179.

Okazaki, S., Skapa, R. and Grande, I. (2008) Capturing global youth: Mobile gaming in the U.S., Spain, and the Czech Republic, Journal of Computer-Mediated Communication 13(4): 827-855.

Orwin, R. G. (1983) A fail-safe N for effect size in meta-analysis, Journal of Educational Statistics 8(2): 157-159.

Paré, G., Trudel, M.-C., Jaana, M. and Kitsiou, S. (2015) Synthesizing information systems knowledge: A typology of literature reviews, Information \& Management 52(2): 183-199.

Park, E., Baek, S., Ohm, J. and Chang, H. J. (2014) Determinants of player acceptance of mobile social network games: an application of extended technology acceptance model, Telematics and Informatics 31(1): 3-15.

Petrova, K. and Qu, H. (2007) Playing mobile games: Consumer perceptions, Proc. 2nd Int. Conf. e-Business (ICE-B 2007), INSTICC Press 209-214. 
RUNNING TITLE: Why do people play games? A meta-analysis

Rosenthal, R. (1979) The "file drawer problem" and tolerance for null results, Psychological Bulletin 86(3): 638-641.

Sabherwal, R., Jeyaraj, A. and Chowa, C. (2006) Information System Success: Individual and Organizational Determinants, Management Science 52(12): 1849-1864.

Salovaara, A. and Tamminen, S. (2009) Acceptance or appropriation? A design-oriented critique on technology acceptance models, in P. Saariluoma \& H. Isomäki, (ed.) Acceptance or appropriation? A design-oriented critique on technology acceptance models, London: Springer, pp. 157-173.

Sjöblom, M., \& Hamari, J. (2017). Why do people watch others play video games? An empirical study on the motivations of twitch users. Computers in Human Behavior.

Schepers, J. and Wetzels, M. (2007) A meta-analysis of the technology acceptance model: Investigating subjective norm and moderation effects, Information \& Management 44(1): 90103.

Schmidt, F. L. and Hunter, J. E. (1977) Development of a general solution to the problem of validity generalization, Journal of Applied Psychology 62(5): 529-540.

Schmidt, F. L. and Hunter, J. E. (1999) Comparison of three meta-analysis methods revisited: An analysis of Johnson, Mullen, and Salas (1995), Journal of Applied Psychology 84(1): 144-148.

Shin, D.-H. (2010) The dynamic user activities in massive multiplayer online role-playing games, International Journal of Human-Computer Interaction 26(4): 317-344. 
RUNNING TITLE: Why do people play games? A meta-analysis

Shin, D.-H. and Shin, Y.-J. (2011) Why do people play social network games?, Computers in Human Behavior 27(2): 852-861.

Soliman, W. and Tuunainen, V. K. (2015) Understanding continued use of crowdsourcing systems: An interpretative study, Journal of Theoretical and Applied Electronic commerce research 10(1): 1-18.

Sun, X. and Law, E. L.-C. (2010) Towards a structural model for intention to play a digital educational game, Lecture Notes in Computer Science 44-55.

Tao, Y.-H., Cheng, C.-J. and Sun, S.-Y. (2009) What influences college students to continue using business simulation games? The Taiwan experience, Computers \& Education 53(3): 929939.

Taylor, T. L. (2012). Raising the Stakes: E-sports and the Professionalization of Computer Gaming. MIT Press.

Teng, C.-I. (2010) Customization, immersion satisfaction, and online gamer loyalty, Computers in Human Behavior 26(6): 1547-1554.

Teng, C.-I. (2013) How do challenges increase customer loyalty to online games?, Cyberpsychology, Behavior, and Social Networking 16(12): 884-891.

Teng, C.-I., Chen, M.-Y., Chen, Y.-J. and Li, Y.-J. (2012) Loyalty due to others: The relationships among challenge, interdependence, and online gamer loyalty, Journal of ComputerMediated Communication 17(4): 489-500. 
RUNNING TITLE: Why do people play games? A meta-analysis

Teng, C.-I. and Chen, W.-W. (2014) Team participation and online gamer loyalty, Electronic Commerce Research and Applications 13(1): 24-31.

Teng, C.-I., Tseng, F.-C., Chen, Y.-S. and Wu, S. (2012) Online gaming misbehaviours and their adverse impact on other gamers, Online Information Review 36(3): 342-358.

Tseng, F.-M. and Wang, C.-Y. (2012) Why don't satisfied consumers show reuse behavior? The context of online games, In Proceedings of Portland International Center for Management of Engineering and Technology: Technology Management for Emerging Technologies, PICMET'12. IEEE. 1627-1639.

Tu, Y.-H. and Hung, K.-M. (2010) The influences of system quality and service quality to consumer satisfaction and loyalty in on-line game industry, In proceedings of Technology Management for Global Economic Growth (PICMET). IEEE. 1-5.

Van der Heijden, H. (2004) User acceptance of hedonic information systems, MIS Quarterly 28(4): 695-704.

Wang, E. S.-T. (2014) Perceived control and gender difference on the relationship between trialability and intent to play new online games, Computers in Human Behavior 30: 315-320.

Wang, H.-Y. and Wang, Y.-S. (2008) Gender differences in the perception and acceptance of online games, British Journal of Educational Technology 39(5): 787-806. 
RUNNING TITLE: Why do people play games? A meta-analysis

Webster, J. and Martocchio, J. J. (1992) Microcomputer playfulness: Development of a measure with workplace implications, MIS Quarterly 16(2): 201-226.

Webster, J. and Watson, R. T. (2002) Analyzing the Past to Prepare for the Future: Writing a Literature Review, MIS Quarterly 26(2): 13-23.

Wei, P.-S. and Lu, H.-P. (2014) Why do people play mobile social games? An examination of network externalities and of uses and gratifications, Internet Research 24(3): 313-331.

Williams, D., Consalvo, M., Caplan, S. and Yee, N. (2009) Looking for gender: Gender roles and behaviors among online gamers, Journal of Communication 59(4): 700-725.

Williams, D., Yee, N. and Caplan, S. E. (2008) Who Plays, How Much, and Why? Debunking the Stereotypical Gamer Profile, Journal of Computer-Mediated Communication 13(4): 9931018.

Wu, J. and Holsapple, C. (2014) Imaginal and emotional experiences in pleasure-oriented IT usage: A hedonic consumption perspective, Information \& Management 51(1): 80-92.

Wu, J. and Li, P. (2007) Why they enjoy using this gaming application, AMCIS 2007 Proceedings.

Wu, J. and Lu, X. (2013) Effects of extrinsic and intrinsic motivators on using utilitarian, hedonic, and dual-purposed information systems: A meta-analysis, Journal of the Association for Information Systems 13(3): 153-191. 
RUNNING TITLE: Why do people play games? A meta-analysis

Wu, J.-H., Wang, S.-C. and Tsai, H.-H. (2010) Falling in love with online games: The uses and gratifications perspective, Computers in Human Behavior 26(6): 1862-1871.

Yee, N. (2006a) Motivations for Play in Online Games, CyberPsychology \& Behavior 9(6): 772775.

Yee, N. (2006b) The demographics, motivations and derived experiences of users of massivelymultiuser online graphical environments, PRESENCE: Teleoperators and Virtual Environments 15: 309-329.

Yi, M. (2004) They got game: Stacks of new releases for hungry video enthusiasts mean it’s boom time for an industry now even bigger than Hollywood, http://www.sfgate.com/news/article/THEY-GOT-GAME-Stacks-of-new-releases-forhungry2663371.php.

Yoon, G., Duff, B. R. and Ryu, S. (2013) Gamers just want to have fun? Toward an understanding of the online game acceptance, Journal of Applied Social Psychology 43(9): 18141826.

Zhang, S., Zhao, J. and Tan, W. (2010) An optimization behavior model for online games acceptance in China, Journal of Information and Computational Science 7(4): 933-940.

Zhao, F. and Fang, X. (2009) Factors affecting online game players' loyalty, Third International Conference, IDGD 2009, Held as Part of HCI International 2009, San Diego, CA, USA, July 1924, 2009. Proceedings 197-206. 
RUNNING TITLE: Why do people play games? A meta-analysis

Zhou, T. (2013) Understanding the effect of flow on user adoption of mobile games, Personal and Ubiquitous Computing 17(4): 741-748.

Zhou, Z., Jin, X.-L., Vogel, D.R., Fang, Y., \& Chen, X. (2011) Individual motivations and demographic differences in social virtual world uses: An exploratory investigation in Second Life, International Journal of Information Management, 31(3): 261-271.

\section{APPENDIX}

\section{A. Complete search string for Scopus}

TITLE-ABS-KEY(("why do people play" OR "why people play" OR "why do people use" OR "why people use" OR "use continuance" OR "continued use" OR "continue using" OR adoption OR acceptance OR "technology adoption" OR "technology acceptance" OR "use intention" OR "intention" OR loyalty) AND (mmo* OR "video game" OR "online game" OR "on-line game" OR "mobile game" OR "social network game" OR "serious game" OR "simulation game" OR "virtual game" OR "social game" OR "exergame" OR "computer game" OR "console game" OR "arcade game" OR "facebook game" OR "casual game" OR "digital game" OR "educational game" OR "first person shooter" OR "multiplayer game")) AND (LIMIT-TO(SUBJAREA, "COMP") OR LIMIT-TO(SUBJAREA, "SOCI") OR LIMIT-TO(SUBJAREA, "ENGI") OR LIMIT-TO(SUBJAREA, "BUSI") OR LIMIT-TO(SUBJAREA, "PSYC") OR LIMITTO(SUBJAREA, "ARTS") OR LIMIT-TO(SUBJAREA, "DECI") OR LIMIT-TO(SUBJAREA, "ECON")). 
RUNNING TITLE: Why do people play games? A meta-analysis 
RUNNING TITLE: Why do people play games? A meta-analysis

\section{B. Tests of heterogeneity}

\begin{tabular}{lllll}
\hline Variables & $\mathrm{Q}$ & $\mathrm{df}(\mathrm{Q})$ & $\mathrm{p}$ & $\mathrm{l}^{2}$ \\
\hline INT $\times$ PEOU & 404.727 & 20 & 0.000 & 95.058 \\
INT $\times$ ATT & 325.413 & 18 & 0.000 & 94.469 \\
INT $\times$ ENJ & 621.542 & 21 & 0.000 & 96.621 \\
INT $\times$ PU & 516.527 & 16 & 0.000 & 96.902 \\
PEOU x PU & 664.663 & 14 & 0.000 & 97.894 \\
INT $\times$ SN & 146.799 & 13 & 0.000 & 91.144 \\
ATT x PEOU & 175.523 & 11 & 0.000 & 93.733 \\
ENJ x PEOU & 302.582 & 11 & 0.000 & 96.365 \\
ATT x ENJ & 86.698 & 10 & 0.000 & 88.466 \\
ATT x PU & 361.462 & 9 & 0.000 & 97.510 \\
ENJ x PU & 350.381 & 8 & 0.000 & 97.717 \\
SN x ATT & 93.773 & 8 & 0.000 & 91.469 \\
SN x ENJ & 107.963 & 7 & 0.000 & 93.516 \\
SN x PEOU & 30.435 & 7 & 0.000 & 77.000 \\
SN x PU & 82.838 & 4 & 0.000 & 95.171 \\
\hline
\end{tabular}


RUNNING TITLE: Why do people play games? A meta-analysis

\section{Structural equation modeling matrices}

Total sample:

\begin{tabular}{|l|l|l|l|l|l|}
\hline & INT & ATT & ENJ & PU & PEOU \\
\hline INT & 1 & & & & \\
\hline ATT & 0.689 & 1 & & & \\
\hline ENJ & 0.586 & 0.596 & 1 & & \\
\hline PU & 0.572 & 0.641 & 0.562 & 1 & \\
\hline PEOU & 0.438 & 0.432 & 0.437 & 0.493 & 1 \\
\hline
\end{tabular}

$\mathrm{n}=5793$

\section{Hedonic games:}

\begin{tabular}{|l|l|l|l|l|l|}
\hline & INT & ATT & ENJ & PU & PEOU \\
\hline INT & 1 & & & & \\
\hline ATT & 0.660 & 1 & & & \\
\hline ENJ & 0.589 & 0.582 & 1 & & \\
\hline PU & 0.392 & 0.423 & 0.492 & 1 & \\
\hline PEOU & 0.325 & 0.338 & 0.396 & 0.294 & 1 \\
\hline
\end{tabular}

$n=4022$

\section{Utilitarian games:}

\begin{tabular}{|l|l|l|l|l|l|}
\hline & INT & ATT & ENJ & PU & PEOU \\
\hline INT & 1 & & & & \\
\hline ATT & 0.751 & 1 & & & \\
\hline ENJ & 0.573 & 0.657 & 1 & & \\
\hline PU & 0.724 & 0.854 & 0.748 & 1 & \\
\hline PEOU & 0.550 & 0.560 & 0.506 & 0.639 & 1 \\
\hline
\end{tabular}

$\mathrm{n}=1114$ 


\section{Meta-analysis calculation formulas (Borenstein et al. 2009)}

1. Use $k$ for number of studies and $n$ for sample sizes $n-3$.

2. Fisher z-transform correlations before calculation: $z=\frac{1}{2} \ln \left(\frac{1+r}{1-r}\right)$

3. Estimate between-studies variance: $T^{2}=\frac{Q-d f}{C}$, where

$$
Q=\sum_{i=1}^{k} n_{i} z_{i}^{2}-\frac{\left(\sum_{i=1}^{k} n_{i} z_{i}\right)^{2}}{\sum_{i=1}^{k} n_{i}}, \quad \quad d f=k-1, \quad C=\sum_{i=1}^{k} n_{i}-\frac{\sum_{i=1}^{k} n_{i}^{2}}{\sum_{i=1}^{k} n_{i}}
$$

4. Random effect model weight: $w=\frac{1}{\frac{1}{n}+\tau^{2}}$

5. Magnitude of effect size estimate: $z=\frac{\sum_{i=1}^{k} w_{i} z_{i}}{\sum_{i=1}^{k} w_{i}}$

6. Standard error of effect size estimate: $S E=\sqrt{\frac{1}{\sum w_{i}}}$

7. $95 \%$ confidence intervals of effect size estimate: $L=z \pm 1.96 * S E$

8. Statistical significance: $Z=\frac{Z}{S E}, \quad p=2(1-\operatorname{NORMDIST}(Z))$

9. Inverse Fisher z-transform back to correlation: $r=\frac{\exp (2 z)-1}{\exp (2 z)+1}$ 